\title{
1 Genome evolution in bacteria isolated from million-year-old subseafloor sediment
}

4 William D. Orsi ${ }^{1,2^{*}}$, Tobias Magritsch ${ }^{1}$, Sergio Vargas ${ }^{1}$, Ömer K. Coskun ${ }^{1}$, Aurele Vuillemin ${ }^{1}$, 5 Sebastian Höhna ${ }^{1,2}$, Gert Wörheide ${ }^{1,2,3}$, Steven D’Hondt ${ }^{4}$, B. Jesse Shapiro ${ }^{5,6,7}$, Paul Carini ${ }^{8^{*}}$

$7 \quad{ }^{1}$ Department of Earth and Environmental Sciences, Paleontology \& Geobiology, Ludwig-Maximilians-Universität

8 München, Richard-Wagner-Strasse 10, 80333 Munich, Germany.

$9{ }^{2}$ GeoBio-CenterLMU, Ludwig-Maximilians-Universität München, Richard-Wagner-Strasse 10, 80333 Munich,

10 Germany.

11 'SNSB- Bayerische Staatssammlung für Paläontologie und Geologie, Richard-Wagner-Strasse 10, 80333 Munich,

12 Germany.

$13{ }^{4}$ Graduate School of Oceanography, University of Rhode Island, 215 South Ferry Road, 02882 Narragansett, USA.

$14{ }^{5}$ Department of Biological Sciences, University of Montreal, QC, Canada

$15{ }^{6}$ Department of Microbiology and Immunology, McGill University, QC, Canada

$16{ }^{7}$ McGill Genome Centre, Canada

$17{ }^{8}$ Department of Environmental Science, the BIO5 Institute, School of Plant Sciences, and the School of Animal \&

18 Comparative Biomedical Science, University of Arizona, Tucson, Arizona USA

19

20

Corresponding authors*:

21 Prof. Dr. William D. Orsi

22 Ludwig-Maximilians-Universität München, Department of Earth and Environmental Sciences,

23 Paleontology \& Geobiology, Richard-Wagner-Strasse 10, 80333 Munich, Germany.

\section{Corresponding authors*:}

26 Dr. Paul Carini

27 Address: University of Arizona, Department of Environmental Science, School of Plant Science, BIO5

28 Institute. Tucson, Arizona 85721

29 E-Mail: paulcarini@arizona.edu

30 Phone/Fax: Phone: 520-621-1646

Running title: Genome evolution in subseafloor bacteria

Keywords: genome evolution; deep biosphere 
37 Significance statement: The nature and extent of genomic evolution in subseafloor microbial

38 populations subsisting for millions of years below the seafloor is unknown. Subseafloor populations have ultra-slow metabolic rates that are hypothesized to restrict reproduction and, consequently, the spread of new traits. Our findings demonstrate that genomes of cultivated

41 bacterial strains from the genus Thalassospira isolated from million-year-old abyssal sediment

42 exhibit greatly reduced levels of homologous recombination, elevated numbers of pseudogenes,

43 and genome-wide evidence of relaxed purifying selection. These substitutions and pseudogenes

44 are fixed into the population, suggesting the genome evolution of these bacteria has been

45 dominated by genetic drift, whereby under long-term physical isolation in small population sizes,

46 and in the absence of homologous recombination, newly acquired mutations accumulate in the

47 genomes of clonal populations over millions of years.

Abstract: Beneath the seafloor, microbial life subsists in isolation from the surface world under persistent energy limitation. The nature and extent of genomic evolution in subseafloor

51 microbes has been unknown. Here we show that the genomes of Thalassospira bacterial

52 populations cultured from million-year-old subseafloor sediments evolve by point mutation, with

53 a relatively low rate of homologous recombination and a high frequency of pseudogenes. Ratios

54 of synonymous to non-synonymous mutation rates correlate with the accumulation of

55 pseudogenes, consistent with a dominant role for genetic drift in the subseafloor strains, but not

56 in type strains of Thalassospira isolated from the surface world. Our findings demonstrate that

57 the long term physical isolation of these bacteria, in the absence of recombination, has resulted in

58 clonal populations that evolve consistent with 'Mullers Ratchet', whereby reduced access to

59 novel genetic material from neighbors has resulted in fixation of new mutations that accumulate

60 in genomes over millions of years.

\section{Main text.}

64 The subseafloor biome contains a large fraction of all prokaryotic cells on Earth totaling circa $10^{29}$

65 cells (1). This biome subsists over geological timescales under persistent energy limitation (2-6). Whether 66 evolution and ecological differentiation occurs in microbial populations below the seafloor has remained 67 controversial. It is generally agreed that extreme energy limitation restricts metabolic activity and growth 
68 (2-6), which are necessary for new mutations to propagate through populations to foster ecological 69 differentiation and speciation (7). However, there has been very little direct examination of this issue at the 70 low metabolic rates and long timescales characteristic of subseafloor life (8). Experimental evidence exists

71 for bacterial evolution under energy limitation on laboratory timescales $(9,10)$, but a recent metagenomic

72 analysis showed that energy limitation and reduced growth restricted the spread of new mutations through

73 microbial communities over 5,000 years in the upper 2 meters of anoxic sediment from Aarhus Bay

74 (Denmark) (11). There have been no direct studies of mutation, homologous recombination, and evolution

75 in microbial communities of the deeper and older sediment that dominates the subseafloor. Here, we used

76 the genomes of bacteria isolated from million-year-old subseafloor abyssal clay sediments to investigate

77 the nature of genome evolution in subseafloor bacteria that persist under extreme energy limitation over 78 long timescales.

Newly acquired mutations of functional significance can sweep through relatively fast-growing bacterial populations in surface world habitats and influence ecological differentiation (12). However, it is unclear whether such sweeps occur in ancient subseafloor sediment given the comparably slow subseafloor bacterial biomass turnover rates that are estimated to be on thousand-year timescales (13). The metabolic rates of microbes persisting in deep-sea abyssal clay are amongst the lowest observed in the subseafloor biosphere, such that these sediments are often oxic through the entire sediment column to the underlying oceanic crust and the microbes live near the low-energy limit to life $(3,4)$. We cored a $15 \mathrm{~m}$ sedimentary sequence of oxygenated abyssal clay at a water depth of $6,000 \mathrm{~m}$ in the North Atlantic where the average sedimentation rate is an estimated 1 meter per million years (14). Thus, the deepest sediment sampled was deposited ca. 15 million years ago (mya). The relatively slow drawdown of $\mathrm{O}_{2}$ with increasing depth at this site (Fig. 1A) primarily reflects oxidation of organic matter by aerobic microbes. Abyssal clay is characterized by very low permeability and extremely small pore diameter (15), which physically isolates the subseafloor microbial communities from the surface and the microbes within it from each other (see 'sediment physical properties' in the SI).

We isolated colony-forming bacteria on petri dishes following an 18-month incubation of sediment and sterile ${ }^{18} \mathrm{O}$-labeled artificial seawater (Fig S1) from 3 and 6 meters below the seafloor (mbsf)(see

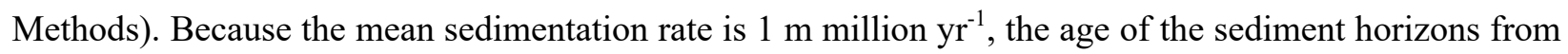
which these bacteria were enriched and isolated are estimated to be 3 and 6 million years old, respectively.

97 The full-length 16S rRNA gene sequences from the isolates had closest similarity (90-99\% sequence 98 identity) to the Alphaproteobacteria Thalassospira xiamenensis and Thalassospira lohafexi previously 99 isolated from marine surface sediment $(16,17)$ and oligotrophic seawater (18) (these previously isolated 100 microbes and their related cultured relatives are referred to as 'type strains' herein). 
Several lines of evidence indicate the Thalassospira isolated from the 3- and 6-mbsf sediment enrichments are endemic to the subseafloor clay and are not a contaminant from the water column or other sources. First, the V4 hypervariable region of the 16S rRNA gene sequences from the sediment slurry enriched Thalassospira cultures share $>99 \%$ sequence identity with an operational taxonomic unit (OTU) 105 previously identified from the in-situ community determined from the frozen samples ('OTU_6', Figure 1B,C). This OTU_6 became ${ }^{18} \mathrm{O}$-labeled during the 18 -month enrichment incubation (atomic ${ }^{18} \mathrm{O}$ enrichment of OTU_6 DNA: 59\%) in the presence of sterile ${ }^{18} \mathrm{O}$-labeled seawater (Fig. S1), a proxy for growing microbes (19), and had an estimated doubling time in the incubation of $36 \pm 1.5$ (mean \pm SD) days. OTU_6 consists of two amplicon sequence variants (ASVs) that cluster with the Thalassospira subseafloor isolates (Otu6_ASV1, Otu6_ASV2), respectively, and are distinguished by a single nucleotide polymorphism (SNP) that is conserved between the ASVs and the subseafloor isolates (Figure 1C). The insitu concentrations of both Thalassospira ASVs have highest abundance (ca. 1,000 16S rRNA gene copies $\mathrm{g}^{-1}$ sediment) below the seafloor between 4 - 6 mbsf, and both Thalassospira ASVs were detected in the 3and 6-mbsf sediment (Figure 1B). This shows that the Thalassospira strains isolated from the 3- and 6mbsf sediment enrichments are derived from the same distinct 16S rRNA gene ASVs present within the insitu communities. The long-term physical isolation of these isolates in the subseafloor (see 'sediment physical properties' in SI), subsisting under uninterrupted energy limitation within the ancient sediment, provides an opportunity to investigate how the relative effects of recombination, nucleotide substitution, and gene decay have shaped the genomes of the cultivated subsurface Thalassospira strains since their burial in the deep-sea clay millions of years ago.

\section{Genome statistics}

123 We sequenced the genomes of ten Thalassospira isolates each from the 3-and 6-mbsf sediment

124 enrichments using a hybrid assembly approach consisting of long-read Nanopore sequencing, corrected

125 and polished via short-read Illumina technologies at $>100 x$ coverage. The mean genome completeness of

126 these hybrid assemblies is estimated to be $99.7 \% \pm 0.3 \%$; (mean $\pm \mathrm{SD}$ ), with most being $100 \%$ complete

127 and representing the complete chromosome (Table S1). The mean length of the new Thalassospira

128 genomes is $4.71 \pm 0.08 \mathrm{Mbp}$ (mean $\pm \mathrm{SD}$ ), with 4,567 \pm 107 (mean $\pm \mathrm{SD}$ ) protein coding genes, and they

129 are assembled to an average of $12 \pm 2$ (mean \pm SD) contigs (Fig. S2 and Table S1). The genome size and

130 the number of protein-encoding genes are similar to those observed within the existing Thalassospira

131 type strains isolated from the surface world (Fig. S2). 


\section{Core genome phylogenomic analysis}

The core genome phylogeny of existing Thalassospira type species, and the newly isolated subseafloor Thalassospira strains, consists of 1,809 orthologous genes and reveals three clades of subseafloor Thalassospira. One clade shares 96-97\% genome-wide average nucleotide identity (ANI), and 99.9\% 16S rRNA gene sequence identity, with T. xiamenensis and T. permensis (Fig. S3). We named isolates in this clade T. xiamenensis strain 'Neogene', after the Neogene eon (2.8 - 23 mya) which covers both estimated ages of sediment ( 3 mya and 6 mya) from which the strains in this clade were isolated. The subseafloor genomes in this clade correspond to the 16S rRNA gene ASV1 detected in the in situ frozen sediment core samples (Fig 1B, C). A second clade contains three isolates from 6 mbsf sediment shared 97\% ANI with T. xiamenensis and T. permensis. Since all isolates in this clade were recovered from ca. 6 mya sediment deposited during the Miocene eon (5.33 - 23 mya), we report them as T. xiamenensis strain 'Miocene' (Fig. S3). However, despite sharing 97\% ANI in the core genome with T. xiamenensis and $T$. permensis (Fig S3), T. xiamenensis strain 'Miocene' only shared 90\% 16S rRNA gene sequence identity with these closest related type strains. The subseafloor genomes in this clade also correspond to ASV1 detected in the in situ frozen sediment core samples (Fig 1B, C). A third clade contains subseafloor Thalassospira cultures isolated only from 3 mbsf sediment and shares 95-96\% ANI with T. lucentensis and T. lohafexi (Fig. S3). The subseafloor genomes in this clade correspond to the 16S rRNA gene ASV2 detected in the in situ frozen sediment core samples (Fig 1B,C). Based on the genetic distinctness of these isolates we consider them to be a new candidate species, according to recently provided criteria based on genome-wide ANI (20). Because all isolates of this third clade were recovered from 3 mya sediment, we propose the candidate name 'Candidatus Thalassospira pliocenensis', named after the Pliocene age (2.58 - 5.33 mya) of the deep-sea clay from which they were isolated. Pangenome analysis revealed that flexible genome content is conserved within each of the three subseafloor clades, providing further evidence that each clade represents a genetically distinct population (Fig S4). Laboratory growth rates of the subseafloor Thalassospira ranged from 0.064 to $0.31 \mathrm{~h}^{-1}$ (Fig. S5).

163 The ratio of nucleotide substitutions originating from mutations versus homologous recombination $(\mathrm{r} / \mathrm{m})$ 164 can be used to measure the relative effect of homologous recombination on the genetic diversification of 165 populations (21). Due to the physical isolation of individual bacterial cells, reduced cell concentrations, 166 and the reduced availability of extracellular DNA for recombination in subseafloor sediments (22) we 167 hypothesized that $\mathrm{r} / \mathrm{m}$ ratios would be lower in the subseafloor Thalassospira populations than in the type strains. To test this, we used an established method (23) to calculate the relative rate of recombination to 
mutation $(R / \theta)$, the mean length of recombined DNA $(\delta)$, and the mean divergence of imported DNA $(v)$

170 for branch tips (existent genomes) and internal nodes (ancestral states) in the Thalassospira core genome 171 phylogeny, which allows for a calculation of $\mathrm{r} / \mathrm{m}(\mathrm{r} / \mathrm{m}=(R / \theta) * \delta * v)$. This analysis showed that in the

172 Thalassospira core genome, the $\mathrm{r} / \mathrm{m}$ is approximately ten times lower in the subseafloor core genome $(\mathrm{r} / \mathrm{m}$

$173=0.078)$ than in the type strains $(\mathrm{r} / \mathrm{m}=0.71)($ Table 1$)$, indicating that homologous recombination plays a

174 much lesser role in the diversification of the subseafloor strains. The $\mathrm{r} / \mathrm{m}$ values of the subseafloor

175 Thalassospira are furthermore anomalously low compared to free-living bacteria isolated from the surface

176 world, which have $\mathrm{r} / \mathrm{m}$ values that range from 0.1-64 (21). Concomitant with the ten-fold lower $\mathrm{r} / \mathrm{m}$ values

177 compared to the type strains (Table 1), the subseafloor Thalassospira core genomes exhibit far fewer

178 numbers of inferred imported DNA from recombination events compared to the Thalassospira type strains

179 and the ancestral states of the last common ancestors shared with the type strains (Fig. 2).

The ancestral recombination signal is not preserved in the genomes of the subseafloor isolates (Fig. 2), which is consistent with a shift away from a recombination-influenced population toward a more clonal population structure since the subseafloor Thalassospira diverged away from the last common ancestor shared with the type strains. We looked for evidence of evolution by investigating pairwise substitution numbers in the subseafloor Thalassospira genomes. We identified tens to thousands of nucleotide differences (single nucleotide polymorphisms [SNPs]) within each subseafloor Thalassospira clade (Fig S6). The SNPs in subseafloor Thalassospira strains were present in a clade-specific manner (Fig S7). But, while the precise SNPs are clade-specific, the SNPs occurred in genes coding for related functions across different clades. These included genes with predicted annotations involved in flagellar motility (FlhB, FliO), transcription (TetR and Fis family transcriptional regulators), cell wall biogenesis (peptidase S41, peptidoglycan DD-metalloendoptidase M23), and transport and metabolism of amino acids and carbohydrates (Fig. S7).

We considered that the observed nucleotide substitutions occurred within the subseafloor populations during the culture enrichment and cultivation process. However, the measured generation times of the Thalassospira (OTU6) in the incubation measured with qPCR (36 \pm 1.5 days; mean $\pm \mathrm{SD})$ indicate an estimated maximum of 15 doublings over the enrichment (see SI). At common bacterial mutation rates of $10^{-9}$ to $10^{-10}$ mutations $\mathrm{bp}^{-1}$ generation ${ }^{-1}(24)$, more than 4,000 generations would be required to obtain the observed nucleotide diversity present in the subsurface Thalassospira genomes (Fig. S8). Thus, newly accumulated mutations in culture are insufficient to explain the observed interpopulation nucleotide diversity between the subseafloor genomes (Fig. S8). The inter-population nucleotide diversity of the subseafloor strains therefore arose during their long-term subsistence in the ancient sediments and is not the result of evolution during the laboratory incubation. 


\section{Substitutions and pseudogenes are fixed in subseafloor populations}

Compared to the type strains, the subseafloor Thalassospira genomes exhibit higher numbers of pseudogenes (non-functional parts of the genome that resemble functional genes), and non-synonymous substitutions (substitutions that alter the amnio acid sequence of a protein). We identified $47.9 \pm 8.57$ (mean $\pm \mathrm{SD}$ ) pseudogenes in the genomes of subseafloor Thalassospira isolates, which is significantly higher than the number of pseudogenes identified in the type strains $(22.1 \pm 5.52$ pseudogenes [mean $\pm \mathrm{SD}$ ]; Table 1 , Figure 3, and Fig. S2) (two-sided T-test: $\mathrm{P}=1.5 \mathrm{E}-10$ ). Similarly, we observed a modest but significant elevation of genome-wide nonsynonymous to synonymous substitution rates $(\mathrm{dN} / \mathrm{dS})$ in the genomes of the subseafloor Thalassospira strains $(0.035 \pm 0.006$; mean $\pm \mathrm{SD})$, relative to the type strains $(0.022 \pm 0.012$; mean $\pm \mathrm{SD}$ ) (two-sided t-test $\mathrm{P}=0.0002$; Table 1, Figure 3 and Fig. S2). Similar to the SNPs (Fig. S7), the composition of pseudogenes occurred in a clade-specific manner (ANOSIM: $\mathrm{P}=0.001$ ) (Fig S9). Compared to the type strains, the predicted annotations of the pseudogenes in the subseafloor Thalassospira genomes are skewed toward those involved in transcription, energy conservation, amino acid and carbohydrate metabolism, and flagellar motility (Fig S9). Moreover, subseafloor genomes have significantly higher numbers of pseudogenes involved in motility (flagellar biosynthesis genes: FliN, FliK, FlhO) compared to the type strains (two-sided t-test: $P=0.003$ ) (Fig S10). is a hallmark of Muller's ratchet (24-28) and is a further indication that the three clades of subsurface Thalassospira are clonal and unable to eliminate deleterious mutations that otherwise would be purged from natural populations that are able to freely recombine. Burial in the sediment millions of years ago resulted in physical isolation of subsurface Thalassospira cells and was the impetus for a transition from freely recombining populations to recombination-limited clonal populations that rarely encounter genetically diverse recombination partners that introduce genetic diversity into the population. Simultaneously, the effective population sizes of subsurface Thalassospira were restricted by the very low flux of bioavailable energy in subseafloor sediment. The reduced energy flux limited the environmental carrying capacity (1), and thus the Thalassospira population size, in this ancient subseafloor clay. The lack of available energy also likely significantly reduced the potential for cellular motility $(5,22)$. The combined effects of physical isolation, low cell concentrations, and little or no motility, resulted in the further reduction of recombination events due to infrequent cell-cell contact. The reduction of homologous

233 Thalassospira populations (Table 1), leading to relaxed purifying selection in the absence of recombination.

234 Although we see elevated dN/dS ratios and an accumulation of pseudogenes across the genomes of 235 subsurface Thalassospira (Fig. 3), some functions appear to be more prone to gene decay than others. For 236 example, genes predicted to be involved in flagellar motility were present in both the SNP (fliO, flhB, flgH; 
Fig. S7) and pseudogene (fliN, fliK, flhO; Fig. S9, S10) analysis, suggesting flagellar motility may become a non-essential trait $(5,22)$ subject to purifying relaxed selection in abyssal clay with (which is characterized by very low permeability and extremely small pore diameter, despite its high porosity [15]). Finally, the accumulation of mutations via Muller's ratchet (24) may explain the reduced growth rates (29) of the subsurface Thalassospira, relative to the type strains (Fig. S5).

\section{Outlook:}

Our findings demonstrate that subseafloor Thalassospira genomes analyzed here have evolved akin to endosymbiotic bacteria, whereby clonal populations also lack homologous recombination and are thus subject to genetic drift whereby deleterious mutations become fixed and Muller's Ratchet (24) eventually leads to the extinction of endosymbiotic bacterial lineages (25). Our genomes show similar signs of evolution, but $\mathrm{dN} / \mathrm{dS}$ ratios observed in the subseafloor Thalassospira genomes are lower than those seen in endosymbiotic bacteria (28) and genome reduction was absent. This could be explained by the subseafloor genomes experiencing a single bottleneck in the form of a burial event followed by a stable but low population size, in contrast to the repeated population bottlenecks experienced by endosymbionts at each insect generation.

Subseafloor cell concentrations are low and decrease substantially with increasing depth (1).

255 Because genetic drift has a stronger effect on populations with small population sizes $(25,28)$, physically

256 isolated microbes experiencing clonal growth and reduced homologous recombination in the deep

257 biosphere may be particularly prone to genetic drift-mediated evolution. Because the subseafloor

258 biosphere contains a large fraction of all bacterial cells on Earth (1), our findings suggest drift-like

259 evolutionary processes in the absence of homologous recombination may be much more widely

260 distributed in nature than previously thought. Future assessments of homologous recombination and drift

261 in single cell genomes from uncultured lineages of bacteria and archaea that comprise most subsurface

262 energy limited communities (30) could be used to assess how widespread this evolutionary mechanism is

263 within the subsurface biosphere.

Acknowledgements. This work was supported primarily by the Deutsche Forschungsgemeinschaft (DFG) project OR 417/1-1 granted to W.D.O. Publication of the manuscript was supported by the LMU

267 Mentoring Program. The expedition was funded by the US National Science Foundation through grant 268 NSF-OCE-1433150 to S.D. This is Center for Dark Energy Biosphere Investigations (C-DEBI) publication 269 number XXX. A portion of this work was performed as part of the LMU Masters Program "Geobiology 270 and Paleobiology" (MGAP). P.C. was supported by the University of Arizona's Technology and Research 
271 Initiative Fund (the Water, Environmental, and Energy Solutions initiative). We thank William F. Martin

272 for comments on the manuscript.

274 Author contributions. W.D.O., P.C., J.S., and G.W. conceived the work and experimental approach.

275 W.D.O., T.M., O.K.C., S.V., P.C., S.H., and A.V. contributed to the laboratory and bioinformatics analyses

276 and experimental work. S.D. provided the samples from the KN223 R/V Knorr oceanographic expedition

277 KN223. All authors discussed and wrote the manuscript and commented on the paper.

279 Competing interests. The authors declare that they have no competing interests.

Supplemental information. Supplemental Table 1, Supplemental Figures S1-S10, References 31-49.

Data and materials availability. Data are publicly available through NCBI BioProject PRJNA473406. The raw genomic sequences reads and genome assemblies are available in SRA BioSample accessions SAMN17168194, SAMN17168195, and SAMN17168196. The 16S data from the frozen core are available in SRA BioSample accessions SAMN10929403 to SAMN10929517. Figures and output files from the pangenomic analysis in Anvio are available online through FigShare

( https://doi.org/10.6084/m9.figshare.13372619). Additional data related to this paper may be requested from the authors.

\section{References}

1. J. Kallmeyer, R. Pockalny, R. R. Adhikari, D. C. Smith, S. D'Hondt, Global distribution of microbial abundance and biomass in subseafloor sediment. Proc Natl Acad Sci U S A 109, 1621316216 (2012).

2. S. D'Hondt, S. Rutherford, A. J. Spivack, Metabolic activity of subsurface life in deep-sea sediments. Science 295, 2067-2070 (2002).

3. S. D'Hondt et al., Subseafloor sedimentary life in the South Pacific Gyre. Proc Natl Acad Sci US A 106, 11651-11656 (2009).

4. H. Roy et al., Aerobic microbial respiration in 86-million-year-old deep-sea red clay. Science 336, 922-925 (2012).

5. T. M. Hoehler, B. B. Jorgensen, Microbial life under extreme energy limitation. Nat Rev Microbiol 11, 83-94 (2013).

6. S. D'Hondt, G. Wang, A. Spivack, The underground economy (Energentic Constraints of Subseafloor Life). Chapter 2.3 in "Earth and Life Processes Discovered from Subseafloor Environment - A Decade of Science Achieved by the Integrated Ocean Drilling Program (IODP)" R. Stein, D. Blackman, F. Inagaki, H. -C. Larson Eds. Pages 127-148. Elsevier, Amsterdam/New York (2014).

6. D'hondt 2014

7 O. X. Cordero, M. F. Polz, Explaining microbial genomic diversity in light of evolutionary ecology. Nat Rev Microbiol 12, 263-273 (2014).

8. J. F. Biddle et al., Prospects for the study of evolution in the deep biosphere. Front Microbiol 2 , 285 (2012). 
9. S. E. Finkel, Long-term survival during stationary phase: evolution and the GASP phenotype. Nat Rev Microbiol 4, 113-120 (2006).

10. L. M. Wick, H. Weilenmann, T. Egli, The apparent clock-like evolution of Escherichia coli in glucose-limited chemostats is reproducible at large but not at small population sizes and can be explained with Monod kinetics. Microbiology (Reading) 148, 2889-2902 (2002).

11. P. Starnawski et al., Microbial community assembly and evolution in subseafloor sediment. Proc Natl Acad Sci U S A 114, 2940-2945 (2017).

12. B. J. Shapiro et al., Population genomics of early events in the ecological differentiation of bacteria. Science 336, 48-51 (2012).

13. B. A. Lomstein, A. T. Langerhuus, S. D'Hondt, B. B. Jorgensen, A. J. Spivack, Endospore abundance, microbial growth and necromass turnover in deep sub-seafloor sediment. NAture 484, 101-104 (2012).

14. A. Vuillemin et al., Archaea dominate oxic subseafloor communities over multimillion-year time scales. Sci Adv 5, eaaw4108 (2019).

15. Y. Morono, et al. Aerobic microbial life persists in oxic marine sediment as old as 101.5 million years, Nature Communications 11, 3626, (2020).

16. M. Li, S. Yang, Q. Lai, Z. Shao, Draft Genome Sequence of Thalassospira xiamenensis Strain MCCC 1A03042(T). Genome Announc 5, (2017).

17. C. Liu, Y. Wu, L. Li, Y. Ma, Z. Shao, Thalassospira xiamenensis sp. nov. and Thalassospira profundimaris sp. nov. Int J Syst Evol Microbiol 57, 316-320 (2007).

18. A. Hutz, K. Schubert, J. Overmann, Thalassospira sp. isolated from the oligotrophic eastern Mediterranean Sea exhibits chemotaxis toward inorganic phosphate during starvation. Appl Environ Microbiol 77, 4412-4421 (2011).

19. B. A. Hungate et al., Quantitative microbial ecology through stable isotope probing. Appl Environ Microbiol 81, 7570-7581 (2015).

20. L. M. Rodriguez-R, K. Konstantinidis, Bypassing cultivation to identify bacterial species. Microbe 9, 111-118 (2014).

21. M. Vos, X. Didelot, A comparison of homologous recombination rates in bacteria and archaea. ISME J 3, 199-208 (2009).

22. M. A. Lever et al., Life under extreme energy limitation: a synthesis of laboratory- and fieldbased investigations. FEMS Microbiol Rev 39, 688-728 (2015).

23. X. Didelot, D. J. Wilson, ClonalFrameML: efficient inference of recombination in whole bacterial genomes. PLoS Comput Biol 11, e1004041 (2015).

24. J. W. Drake, B. Charlesworth, D. Charlesworth, J. F. Crow, Rates of spontaneous mutation. Genetics 148, 1667-1686 (1998).

24 H. J. Muller, The relation of recombination to mutational advance. Mutat Res 106, 2-9 (1964).

25. J. P. McCutcheon, N. A. Moran, Extreme genome reduction in symbiotic bacteria. Nat Rev Microbiol 10, 13-26 (2011).

26. H. Ochman, L. M. Davalos, The nature and dynamics of bacterial genomes. Science 311, 17301733 (2006).

27. N. A. Moran, Accelerated evolution and Muller's rachet in endosymbiotic bacteria. Proc Natl Acad Sci U S A 93, 2873-2878 (1996).

28. C. H. Kuo, N. A. Moran, H. Ochman, The consequences of genetic drift for bacterial genome complexity. Genome Res 19, 1450-1454 (2009).

29. D. I. Andersson, D. Hughes, Muller's rachet decreases fitness of a DNA-based microbe. Proc Natl Acad Sci U S A 93, 906-907 (1996).

30. K. G. Lloyd, A. D. Steen, J. Ladau, J. Yin, L. Crosby, Phylogenetically Novel Uncultured Microbial Cells Dominate Earth Microbiomes. mSystems 3, (2018). 


\section{Figure legends}

Figure 1: Isolated subsurface Thalassospira are most abundant at 3-7 mbsf and distinct from related type strains isolated from overlying water and sediments. (A) Vertical profile of total $16 \mathrm{~S}$ rRNA gene concentrations determined via qPCR (squares), and oxygen concentrations (circles). 16S rRNA gene concentration points are the average abundances of three technical qPCR replicates with ranges shown with error bars. (B) qPCR-normalized average concentrations of the Thalassospira affiliated 'Otu6' ASVs. Error bars are ranges from three technical qPCR replicates. Asterisks mark the depths for the long term ${ }^{18} \mathrm{O}$-water incubation experiments, enrichments, and cultivation. (C) Maximum likelihood (PhyML) phylogenetic analysis of the Thalassospira 16S rRNA gene ASVs (V4 hypervariable region), together with subseafloor and type strain Thalassospira 16S rRNA gene V4 regions. The presence of the SNP is displayed. Black, grey, and white dots at the nodes represent $>90 \%,>70 \%,>50 \%$ bootstrap support, respectively. populations. The maximum likelihood (PhyML) phylogenetic tree is based on a concatenated alignment of 1,809 genes conserved across all Thalassospira genomes ('core genes'). Black circles on nodes represent bootstrap values $>95 \%$. The position of recombination events in the core genome are represented by dark blue dots. Positions of low nucleotide diversity and no recombination events in the core genome are shown in light blue. Nucleotide diversity at specific sites in the core genome are illustrated with a color gradient (white: less diversity, orange: more diversity). Histograms on the right display the total number of recombination events (imports) in each genome sequence, and ancestral state reconstructions (internal nodes), as detected by ClonalFrameML (23). increasing $\mathrm{dN} / \mathrm{dS}$ ratios compared to the type strains. Linear regressions for type strains, subseafloor strains, and all strains are displayed.

Table 1. The contributions of recombination and mutation to nucleotide diversity in subseafloor populations. The results from ClonalFrameML (23) analysis used to calculate the relative contributions of recombination and mutation in the core genome $(\mathrm{r} / \mathrm{m}) . R / \theta$ : the relative rate of recombination compared to mutation, $\delta$ : the average length of recombined (imported) DNA, $v$ : mean divergence of

394 imported DNA. Also displayed are the average number of pseudogenes and dN/dS ratios (+/- standard 
bioRxiv preprint doi: https://doi.org/10.1101/2020.12.19.423498; this version posted January 8, 2021. The copyright holder for this preprint (which was not certified by peer review) is the author/funder, who has granted bioRxiv a license to display the preprint in perpetuity. It is made available under aCC-BY-ND 4.0 International license.

400

\section{$401 \quad$ Figure 1}

402

A.

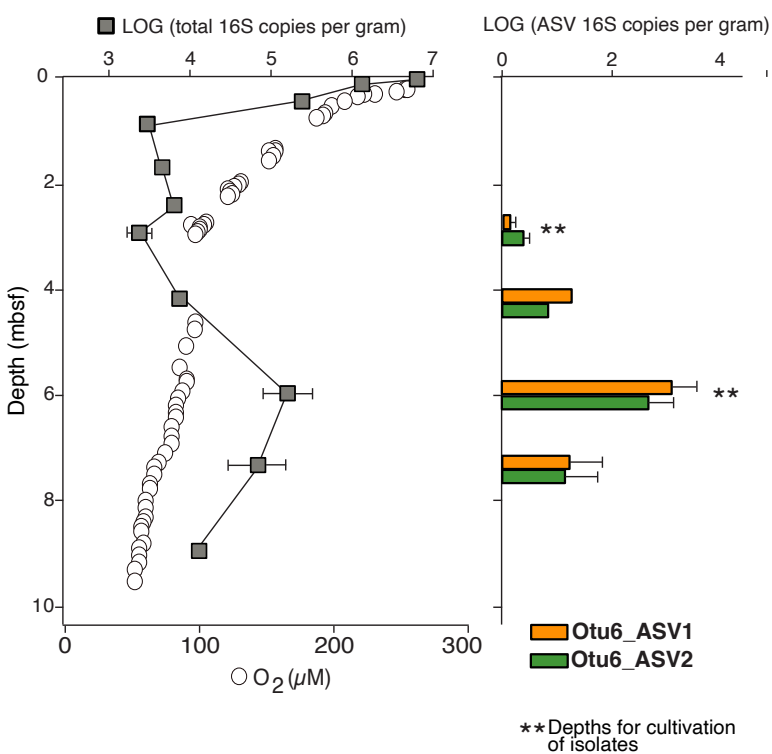

C.

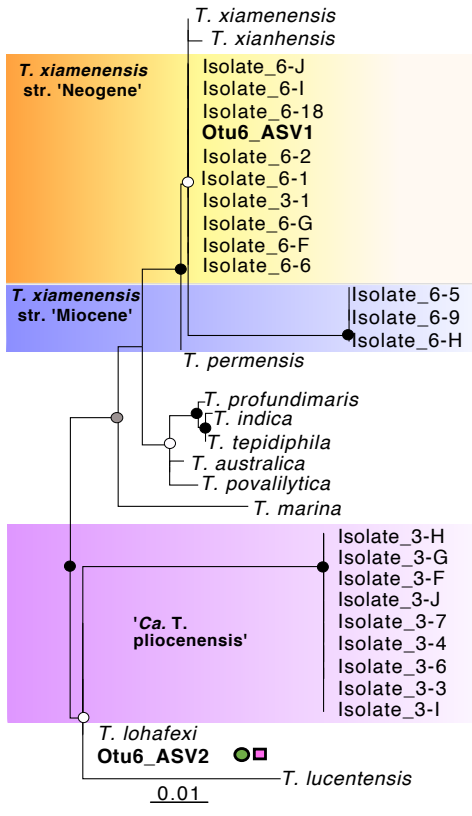

Position in V4 16S alignment

130

SNP 141

CTGCAG:GACTA

CTGCA:GACTA

CTGCAGIGACTA

CTGCAGI ACTA

CTGCAG:

CTCLIGIOCTA

CTGCA:GIUCTA

CTGCA:GUACTA

CTCAGACTA

TGCA:GACTA

CTGCA:G ACTA

CT GCA:G ACTA

CTGCA:GG ACTA

CTGCA:GACTA

CT G C A:A:G ACTA

CT GCA:A:G ACTA

CTGCA:A:G ACTA

CTGCA:A:G ACTA

CTGCA:A:G ACTA

CTGCA:A:G ACTA

CT GCA:A:G ACT

CTGCA:A:GACT

CTGCA:A:GACTA

CT GCA:AUACTA

CTGCA

CT

CTGCA:A ACTA

CT

CTGCA:GACTA

CTGCAGACTA

CTGCA:A:GACTA

O Detected at $3 \mathrm{mbsf}$

403

404

405

406

407

408

409

410

411

412

413 
bioRxiv preprint doi: https://doi org/10.1101/2020 12 19.423498; this version posted January 8,2021 . The copyright holder for this preprint (which was not certified by peer review) is the author/funder, who has granted bioRxiv a license to display the preprint in perpetuity. It is made available under aCC-BY-ND 4.0 International license.

\section{Table 1}

\begin{tabular}{|lccccccc|}
\hline \multicolumn{1}{|c}{ Group } & \# strains & $\boldsymbol{R} / \boldsymbol{\theta}$ & $\boldsymbol{\delta}$ & $\boldsymbol{V}$ & $\mathbf{r} / \mathbf{m}$ & \# pseudogenes & dN/dS \\
\hline All subseafloor and type strains & 34 & 0.053 & 244 & 0.055 & 0.71 & $37(+/-8)$ & $0.025(+/-0.011)$ \\
Type strains & 13 & 0.04 & 333 & 0.053 & 0.71 & $21(+/-3)$ & $0.022(+/-0.01)$ \\
Subseafloor & 21 & 0.006 & 500 & 0.026 & 0.078 & $48(+/-4)^{\star \star \star \star}$ & $0.038(+/-0.007)^{\star \star}$ \\
\hline
\end{tabular}

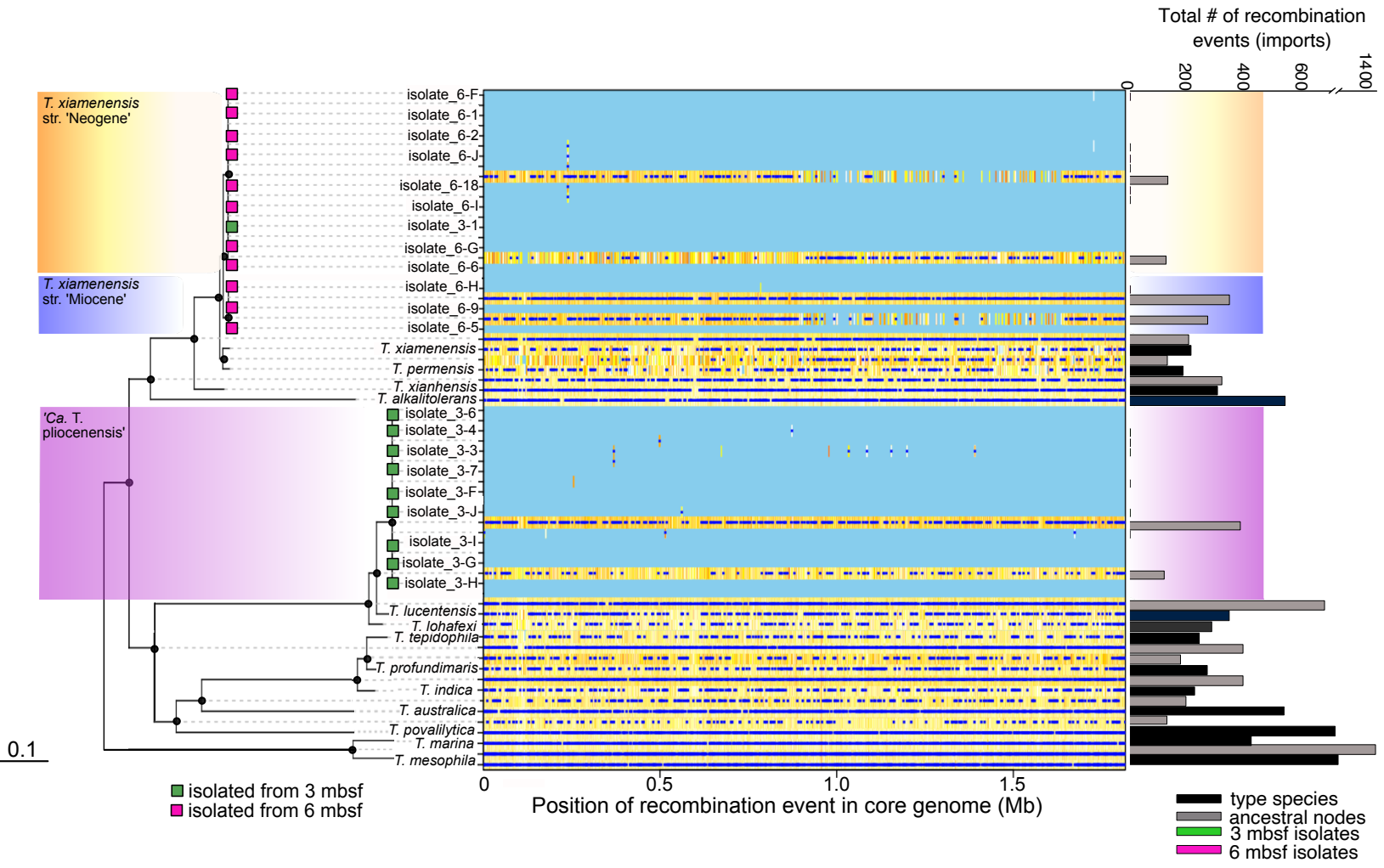


bioRxiv preprint doi: https://doi.org/10.1101/2020 12.19.423498; this version posted January 8, 2021. The copyright holder for this preprint (which was not certified by peer review) is the author/funder, who has granted bioRxiv a license to display the preprint in perpetuity. It is made available under aCC-BY-ND 4.0 International license.

\section{$434 \quad$ Figure 3}

435

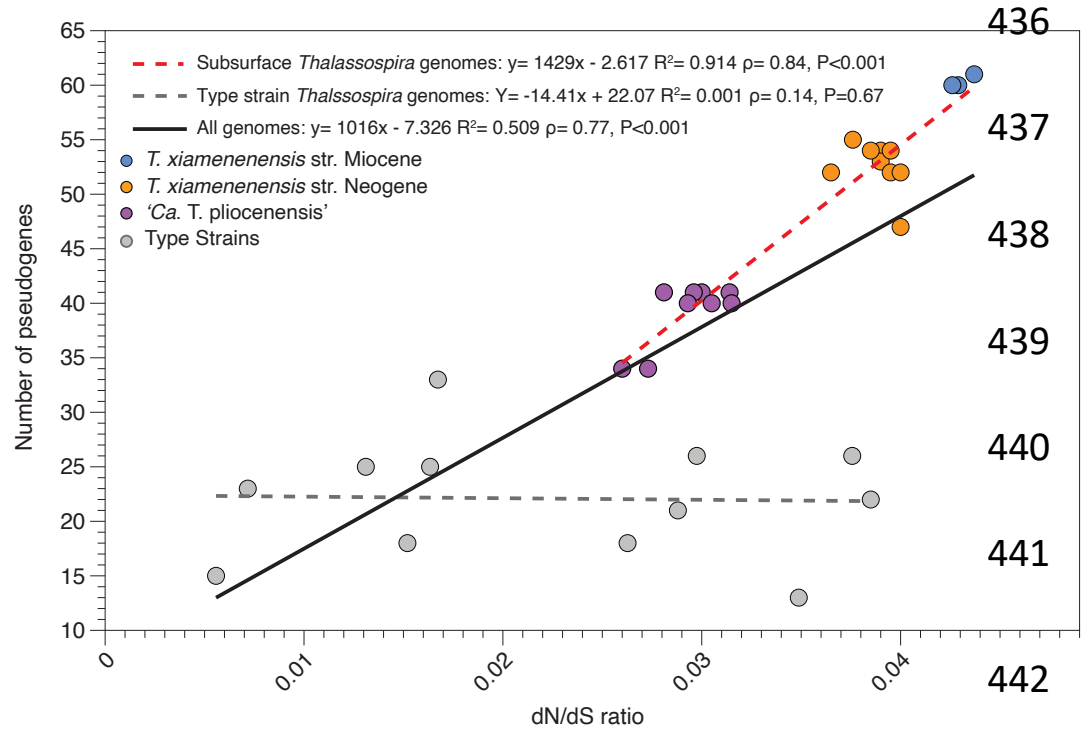




\section{Genome evolution in bacteria isolated from million-year-old subseafloor} sediments

William D. Orsi ${ }^{1,2^{*}}$, Tobias Magritsch ${ }^{1}$, Sergio Vargas ${ }^{1}$, Ömer K. Coskun ${ }^{1}$, Aurele Vuillemin ${ }^{1}$, München, Richard-Wagner-Strasse 10, 80333 Munich, Germany.

462 ${ }^{3}$ SNSB- Bayerische Staatssammlung für Paläontologie und Geologie, Richard-Wagner-Strasse 10, 80333 Munich, 463 Germany.

$464{ }^{4}$ Graduate School of Oceanography, University of Rhode Island, 215 South Ferry Road, 02882 Narragansett, USA.

$465{ }^{5}$ Department of Biological Sciences, University of Montreal, QC, Canada

$466{ }^{6}$ Department of Microbiology and Immunology, McGill University, QC, Canada

$467{ }^{7}$ McGill Genome Centre, Canada

$468{ }^{8}$ Department of Environmental Science, the BIO5 Institute, School of Plant Sciences, and the School of Comparative 
bioRxiv preprint doi: https://doi.org/10.1101/2020.12 19.423498; this version posted January 8, 2021. The copyright holder for this preprint (which was not certified by peer review) is the author/funder, who has granted bioRxiv a license to display the preprint in perpetuity. It is made available under aCC-BY-ND 4.0 International license.

Table S1. Genome summary statistics.

480

\begin{tabular}{|c|c|c|c|c|c|c|c|c|c|c|c|c|}
\hline Group & isolation depth & isolate & N50 contig size (bp) & size (Mb) & \# contigs & GC content & completeness (CheckM) & Contamination (CheckM) & predicted genome size (Mb) & \# PEGs & Predicted \#f PEGs & \% core genome \\
\hline \multirow{9}{*}{ Ca. T. pliocenensis' } & \multirow{9}{*}{$3 \mathrm{mbsf}$} & 3.4 & 649,568 & 4.7 & 13 & 53.5 & $100 \%$ & $0 \%$ & 4.7 & 4463 & 4463 & 40.5 \\
\hline & & 3.7 & $1,392,694$ & 4.73 & 13 & 53.5 & $100 \%$ & $0 \%$ & 4.73 & 4463 & 4463 & 40.5 \\
\hline & & 3.F & $1,049,738$ & 4.64 & 13 & 53.5 & $100 \%$ & $0 \%$ & 4.64 & 4463 & 4463 & 40.5 \\
\hline & & 3.6 & $1,232,970$ & 4.64 & 13 & 53.5 & $100 \%$ & $0 \%$ & 4.64 & 4463 & 4463 & 40.5 \\
\hline & & $3 . \mathrm{H}$ & 994,209 & 4.64 & 13 & 53.5 & $100 \%$ & $0 \%$ & 4.64 & 4463 & 4463 & 40.5 \\
\hline & & 3.1 & 735,219 & 4.64 & 11 & 53.5 & $100 \%$ & $0 \%$ & 4.64 & 4466 & 4466 & 40.5 \\
\hline & & 3.J & $1,232,974$ & 4.64 & 11 & 53.5 & $100 \%$ & $0 \%$ & 4.64 & 4466 & 4466 & 40.5 \\
\hline & & 3.3 & 556,527 & 4.64 & 13 & 53.5 & $100 \%$ & $0 \%$ & 4.64 & 4463 & 4463 & 40.5 \\
\hline & & 3.6 & $1,047,050$ & 4.63 & 13 & 53.5 & $100 \%$ & $0 \%$ & 4.63 & 4463 & 4463 & 40.5 \\
\hline \multirow{9}{*}{ T. xiamenensis 'Neogene' } & \multirow{8}{*}{$6 \mathrm{mbsf}$} & 6.1 & 823,074 & 4.74 & 10 & 54.8 & $99.50 \%$ & $0 \%$ & 4.76 & 4651 & 4674 & 38.9 \\
\hline & & 6.2 & 671,859 & 4.59 & 9 & 54.8 & $97 \%$ & $0 \%$ & 4.73 & 4481 & 4620 & 40.4 \\
\hline & & 6.6 & $1,045,808$ & 4.74 & 12 & 54.8 & $100 \%$ & $0 \%$ & 4.74 & 4622 & 4622 & 39.1 \\
\hline & & 6.18 & $1,220,195$ & 4.75 & 14 & 54.8 & $100 \%$ & $0 \%$ & 4.75 & 4651 & 4651 & 38.9 \\
\hline & & $6 . \mathrm{F}$ & $1,372,017$ & 4.74 & 9 & 54.8 & $99.50 \%$ & $0 \%$ & 4.76 & 4637 & 4660 & 39.0 \\
\hline & & 6.6 & $1,372,000$ & 4.73 & 7 & 54.8 & $99.50 \%$ & $0 \%$ & 4.75 & 4636 & 4659 & 39.0 \\
\hline & & 6.1 & $1,156,923$ & 4.75 & 11 & 54.8 & $100 \%$ & $0 \%$ & 4.75 & 4651 & 4651 & 38.9 \\
\hline & & 6.J & $1,392,823$ & 4.64 & 8 & 54.8 & $98 \%$ & $0 \%$ & 4.76 & 4555 & 4672 & 39.7 \\
\hline & $3 \mathrm{mbsf}$ & 3.1 & $1,245,526$ & 4.75 & 12 & 54.8 & $100 \%$ & $0 \%$ & 4.75 & 4673 & 4673 & 38.7 \\
\hline \multirow{3}{*}{ T. xiamenensis 'Miocene' } & \multirow{3}{*}{$6 \mathrm{mbsf}$} & 6.5 & 484,976 & 4.87 & 16 & 54.7 & $100 \%$ & $0 \%$ & 4.87 & 4730 & 4730 & 38.2 \\
\hline & & 6.9 & 484,974 & 4.87 & 15 & 54.7 & $100 \%$ & $0 \%$ & 4.87 & 4728 & 4728 & 38.3 \\
\hline & & $6 . \mathrm{H}$ & 484,664 & 4.87 & 16 & 54.6 & $100 \%$ & $0 \%$ & 4.87 & 4732 & 4732 & 38.2 \\
\hline
\end{tabular}

481

482

483

484

485

486

487

488

489

490

491

492

493

494

495

496

497

498

499

500

501 
502 Figure S1. Top panel: ${ }^{18} \mathrm{O}$-labeling of 16S rRNA genes from the Thalassospira OTU6 (see

503 Figure 1), after 7 and 18 months of incubation with ${ }^{18} \mathrm{O}$-labeled water from the 3 mbsf sediment

504 (data originally published in Vuillemin et al., 2019). Middle panel: Oxygen consumption over

505 time in the 18 month slurry from the 3 mbsf incubation (filled circles), and slurries containing

506 labeled water and autoclaved sediment (killed control). Bottom photo: cultivation of colony

507 forming bacteria on solid media after the 18 month incubation of sediment slurries in sterile ${ }^{18} \mathrm{O}$ -

508 labeled artificial sea water. No bacterial colonies formed on petri dishes that were inoculated

509 with the killed control slurries.
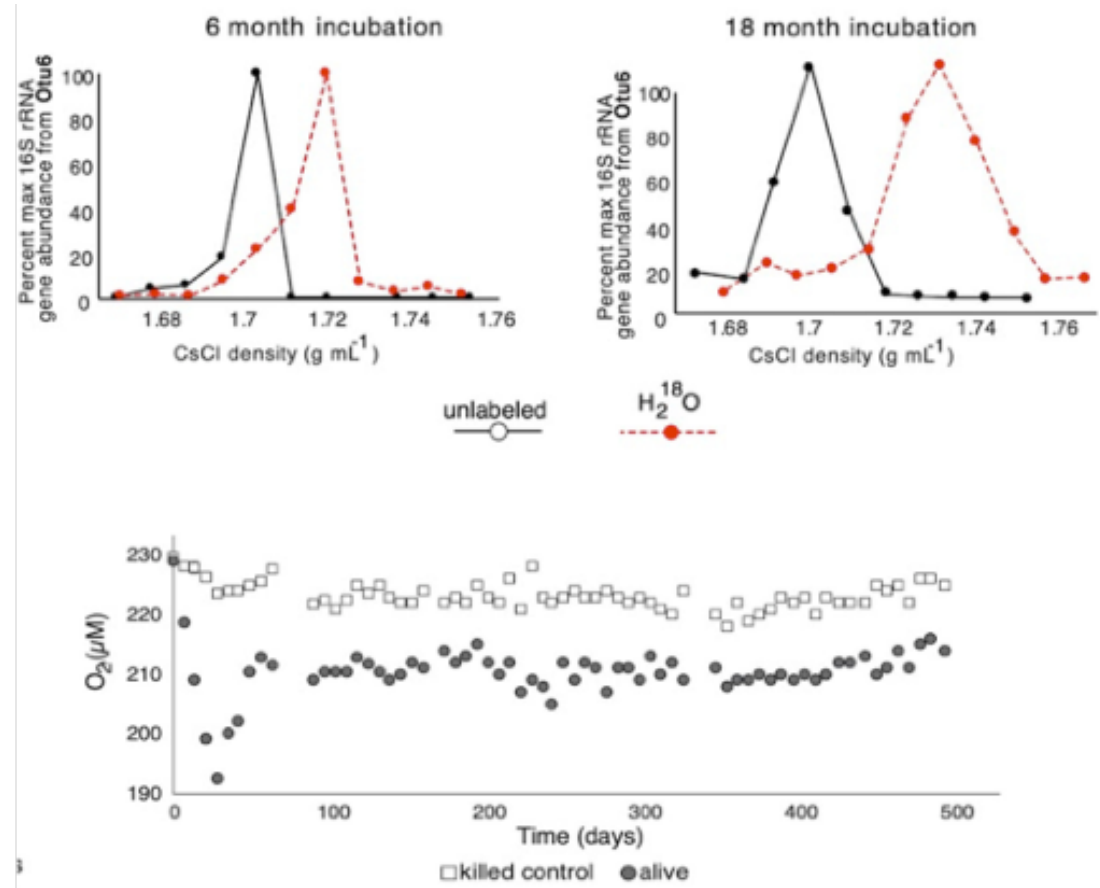

520

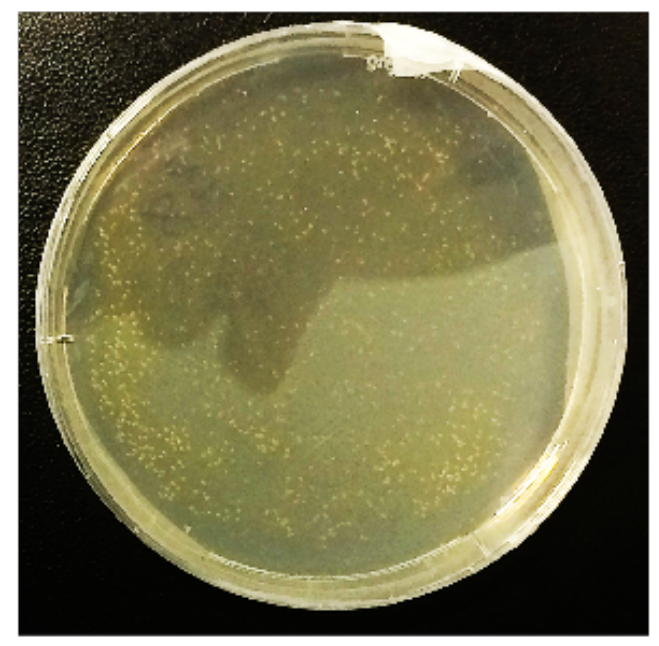


527 Figure S2: Summary of genome properties for Thalassospira strains used in this study.

528 Points are derived from the analysis of existing genome sequences (for "Type" strains), and new

529 high-quality draft genomes sequenced as part of this study. Box plots illustrate interquartile

530 range $\pm 1.5 \times$ interquartile range. The horizontal line in each box plot is the median.

531
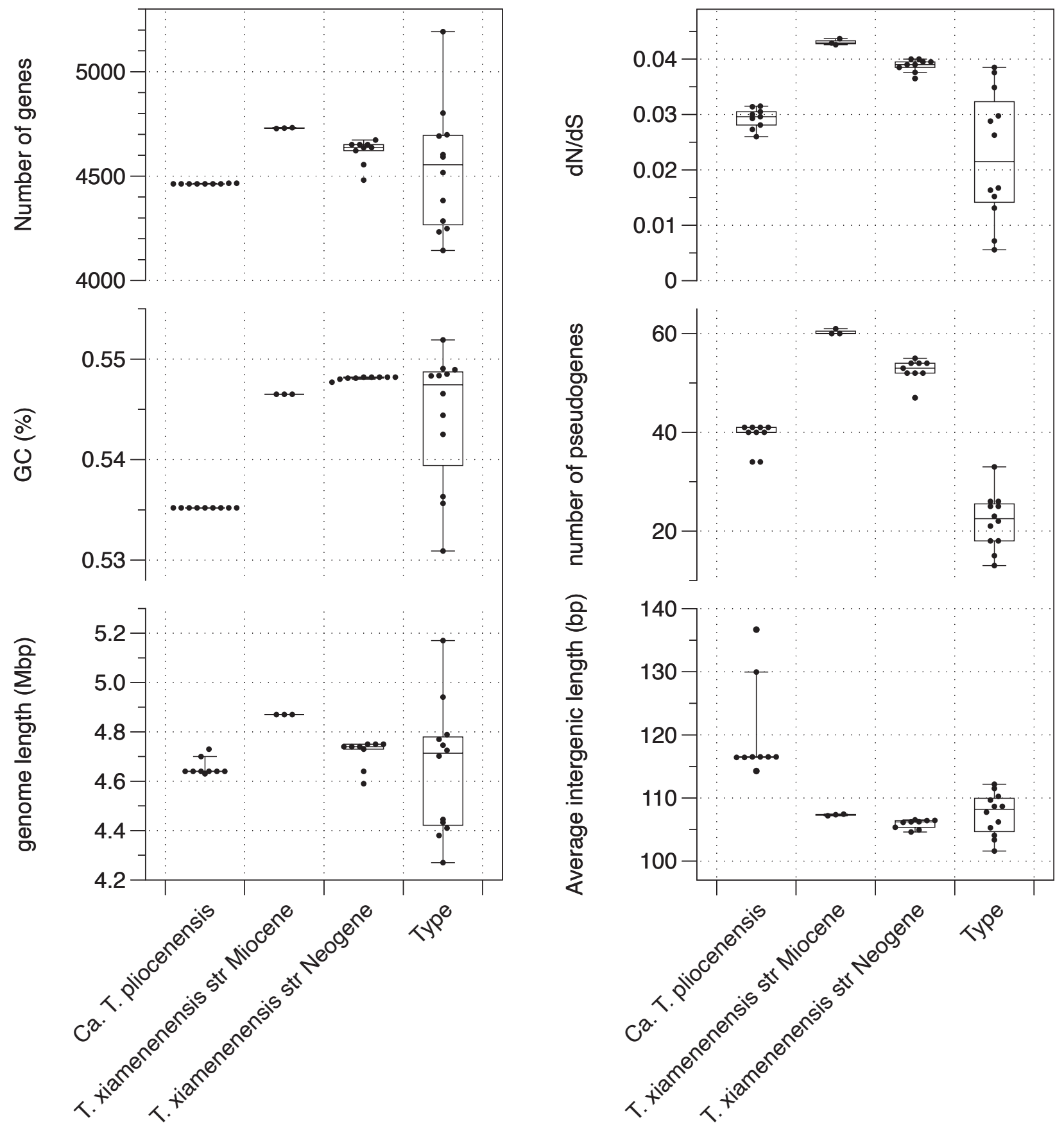
Figure S3. Average nucleotide identity (ANI) and the core genome phylogeny. The tree is

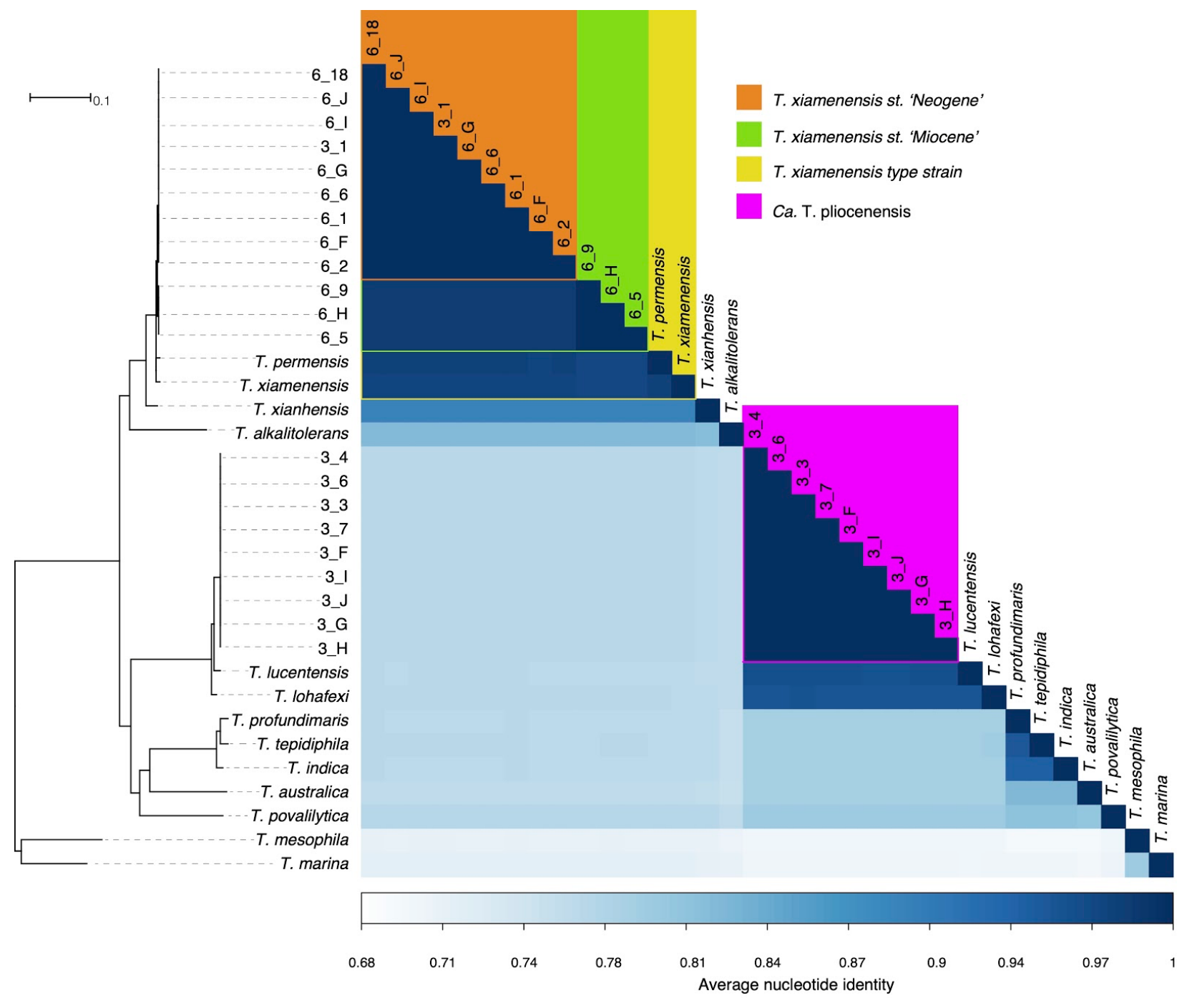


Figure S4: Pangenome analysis of all Thalassospira genomes included in the study. The internal dendrogram is a UPGMA based on the presence/absence of shared gene orthologs. Black bars in the first (inner) 34 circles show the occurrence of gene clusters in the genome of Thalassospira species. Grey areas and light colors in the circles represent gene clusters that were detected in the corresponding genome. The next eight bars show statistics for the pangenome analysis of each individual gene cluster (inner circle to outer circle) \# contributing genomes: \# of genomes that has a hit in a gene cluster, (GC), max \# paralogs, single copy gene clusters (SCG), Functional Homogeneity index, Geometric homogeneity index, combined homogeneity index, presence of a COG functional assignment. The categories on the right side (below dendrogram) show the totals per genome for \# of gene clusters found in each genome, Num genes per kbp: Number of genes per kilobase pairs of genome. Redundancy: Multiple occurrence of single copy genes in a genome, Completeness: Calculated from the occurrences of single copy gene set in a genome

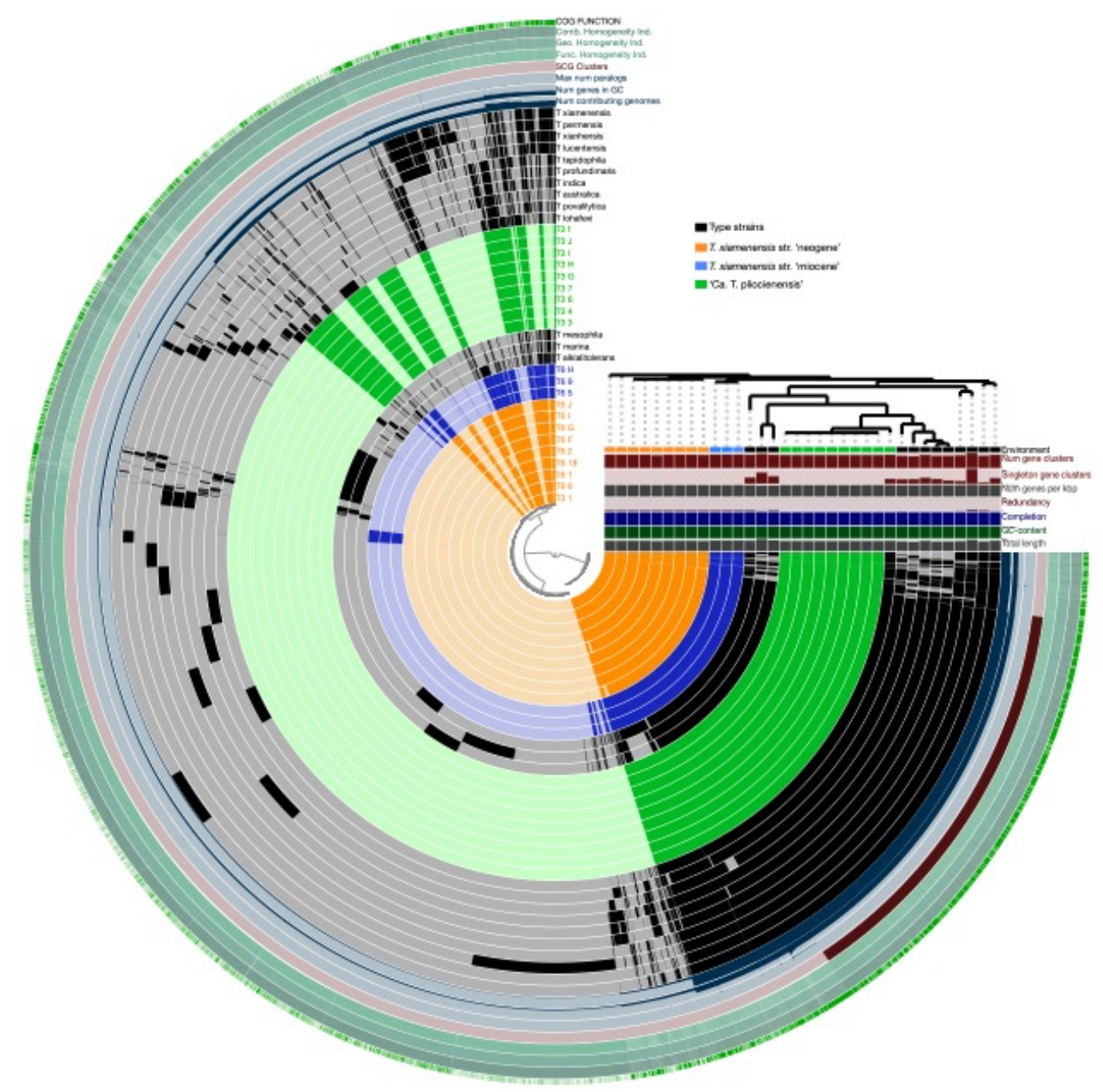


561 Figure S5. Laboratory growth rates of subsurface Thalassospira isolates in comparison to

562 type strain $T$. xiamenenensis. Box plots illustrate interquartile range $\pm 1.5 \times$ interquartile range.

563 The horizontal line in each box plot is the median. For subsurface strains, growth rates were

564 calculated for each strain across three independent experiments. For the T. xiamenenesis type

565 strain, growth rates were calculated from triplicate flasks of one experiment.

566

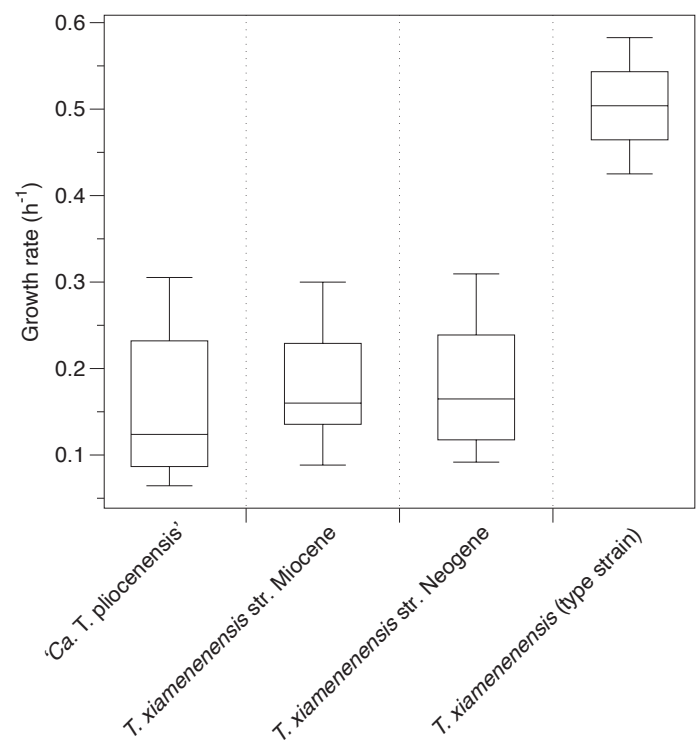

568

569 Figure S6. The number of SNPs between pairs of subseafloor Thalassospira genomes.

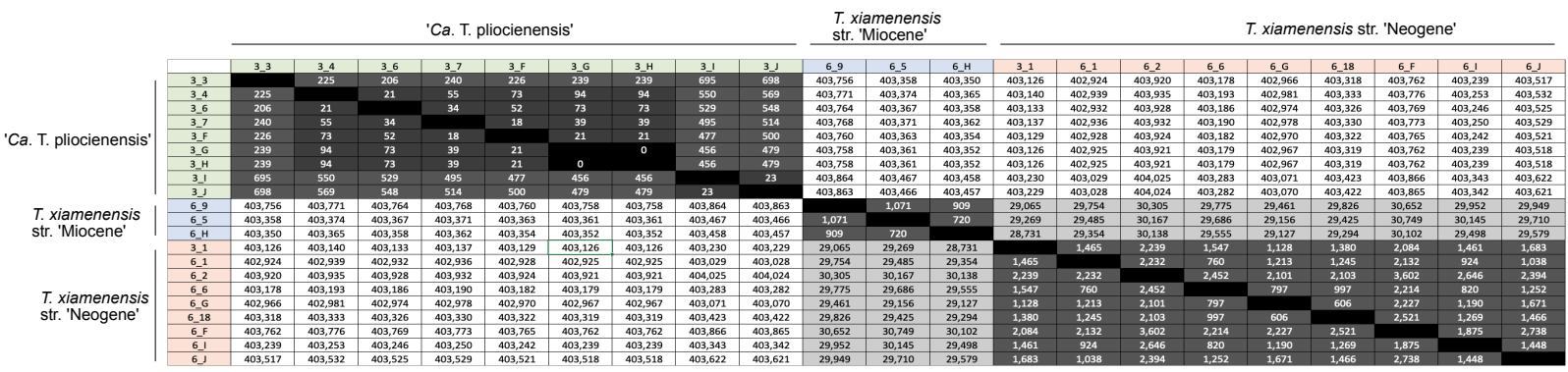


570 Figure S7. The number of interpopulation SNPs at different positions in the core genome

571 alignment, for each of the three subseafloor populations. The gene annotations to the

572 corresponding regions are shown.

T. xiamenensis str. 'neogene'

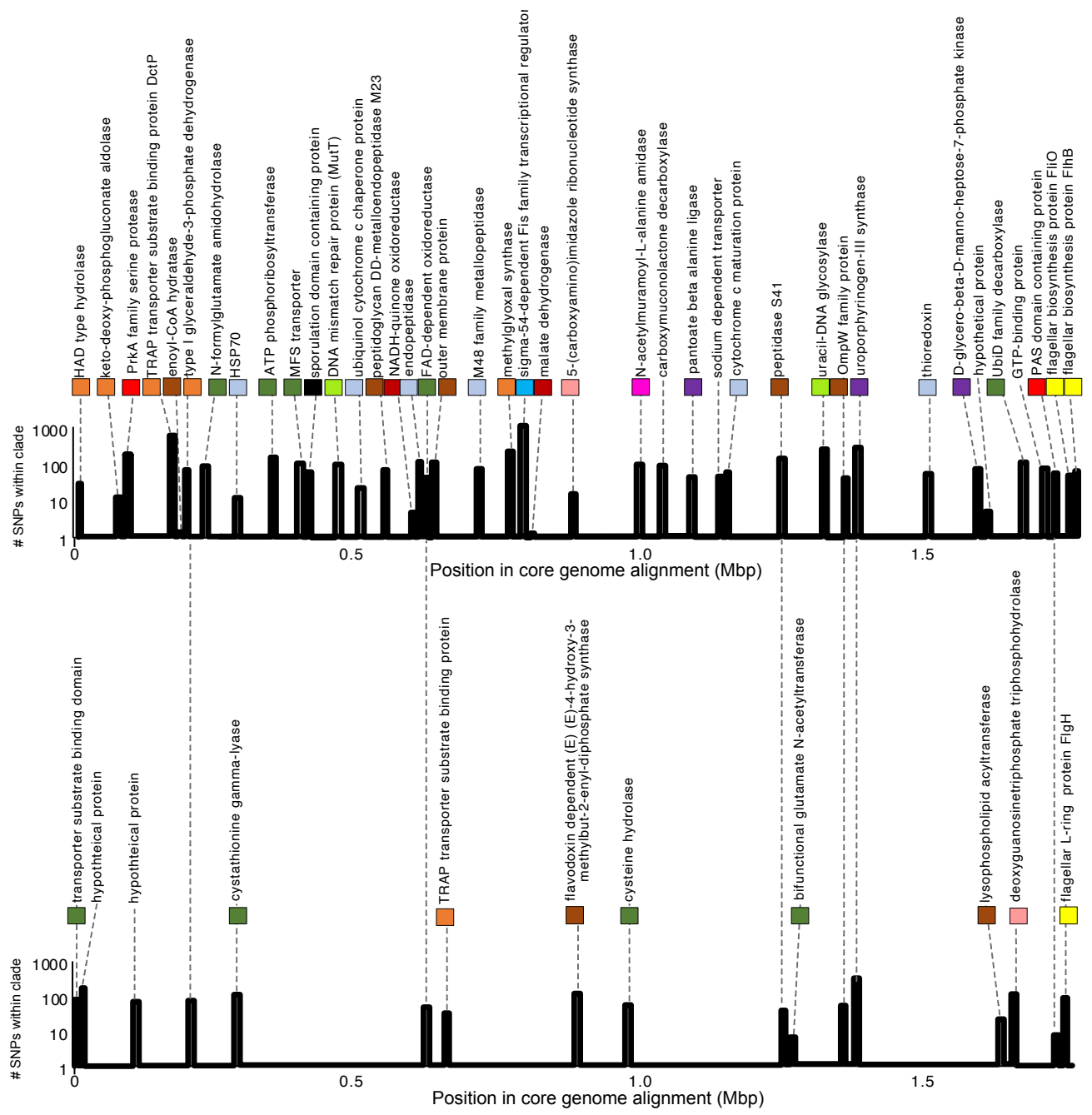

T. xiamenensis str. 'miocene'

Position in core genome alignment (Mbp)

'Ca. T. pliocenensis'
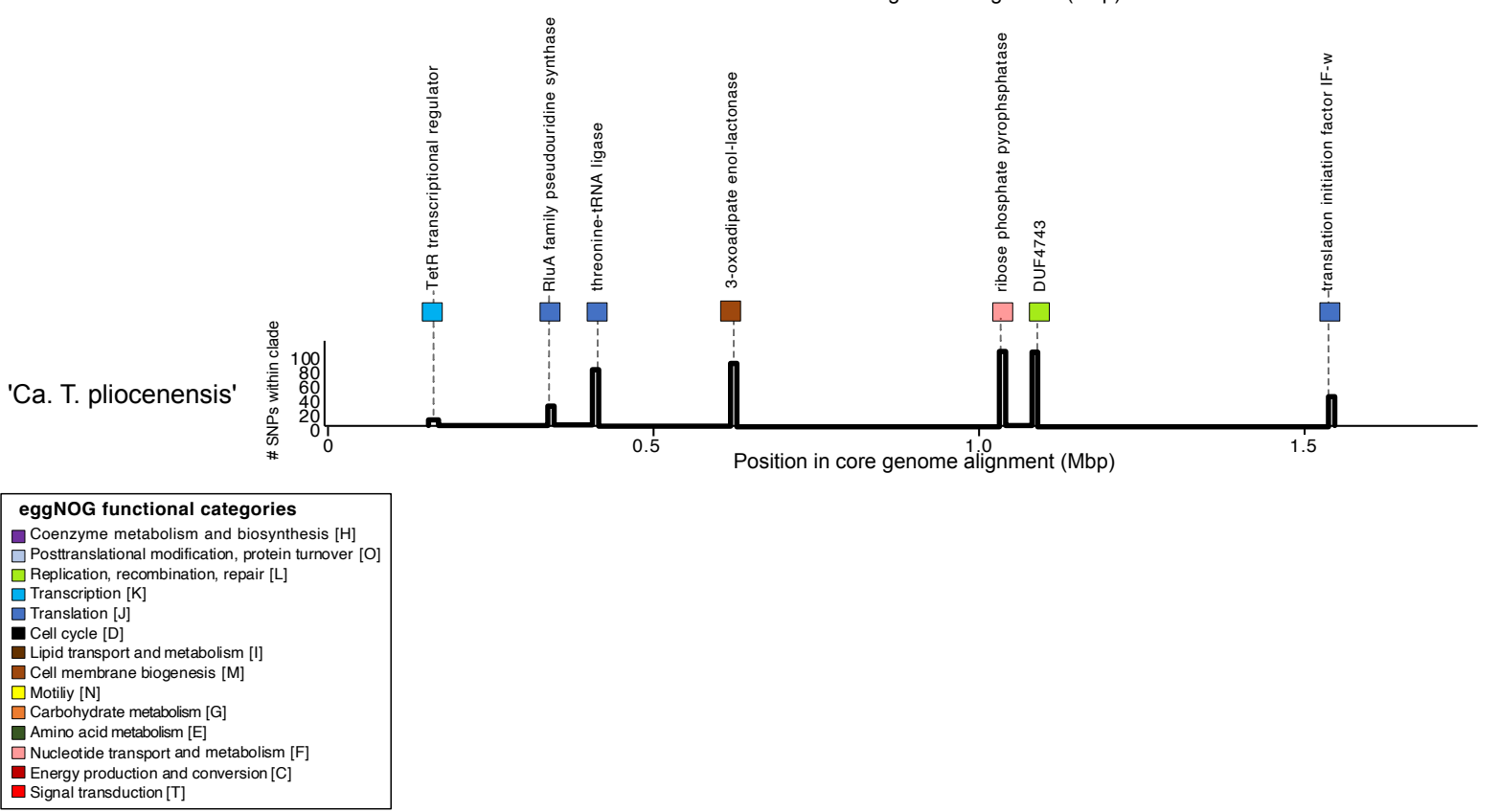
Figure S8: Interpopulation nucleotide diversity did not arise during laboratory cultivation. (A) Model of the number of mutations expected per genome (4.7 Mbp) as a function of total number of generations at five different mutation rates. Shading depicts the range of observed nucleotide diversity in subseafloor Thalassospira genomes (number of pairwise SNPs) as described in panel B. (B) The distribution of interpopulation nucleotide diversity. Points are the number of pairwise SNPs detected in subseafloor Thalassospira genomes. Box plots illustrate interquartile range $\pm 1.5 \times$ interquartile range. The horizontal line in each box plot is the median.

580

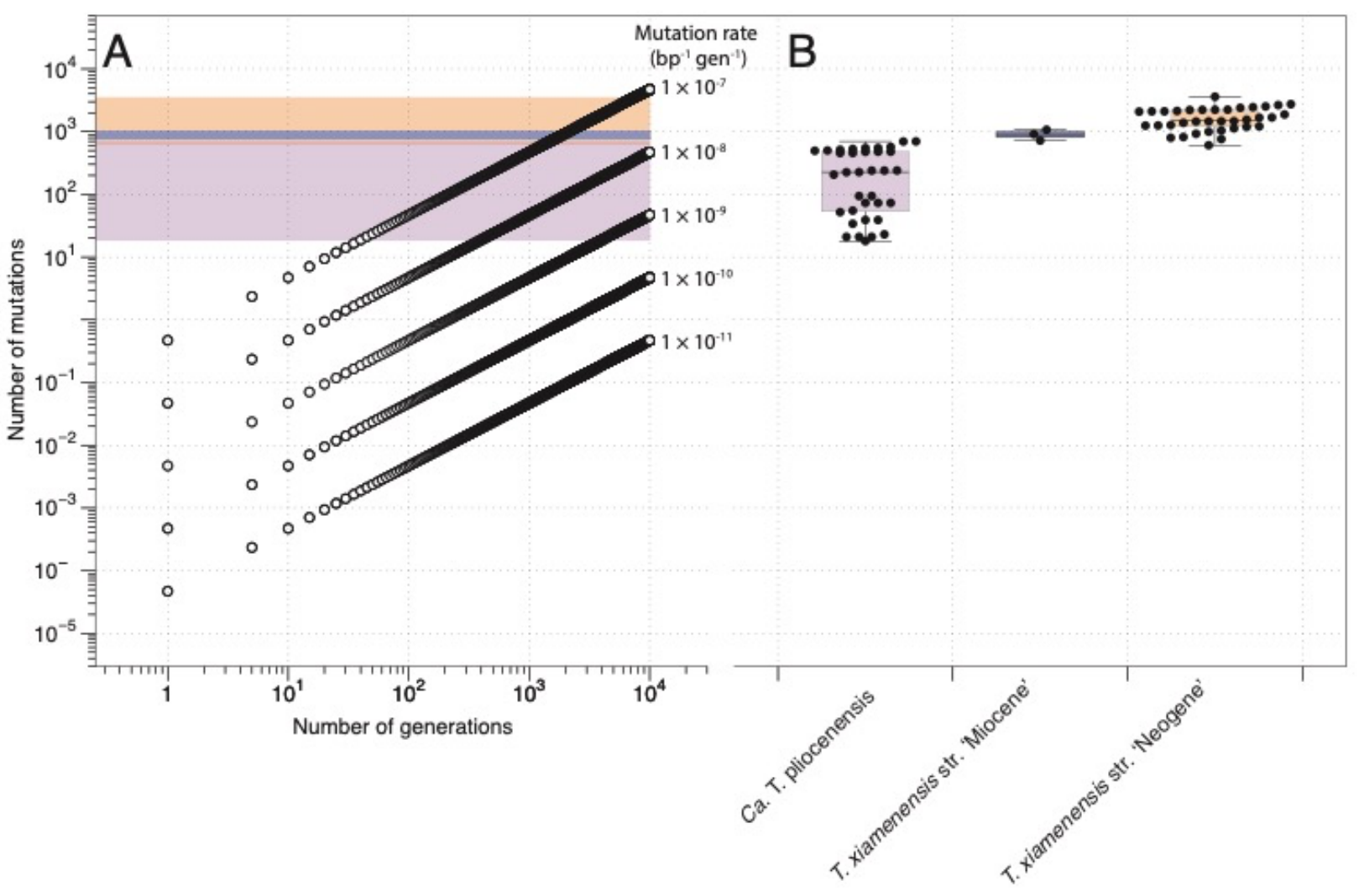


588 Figure S9: The heatmap shows the presence/absence of pseudogenes in the subseafloor genomes 589 and the presence of these pseudogenes in type strains. Functional annotation (against eggNOG) 590 of pseudogenes found in the subseafloor genomes only are compared to functional annotations of 591 pseudogenes found in both the subseafloor and type strains.

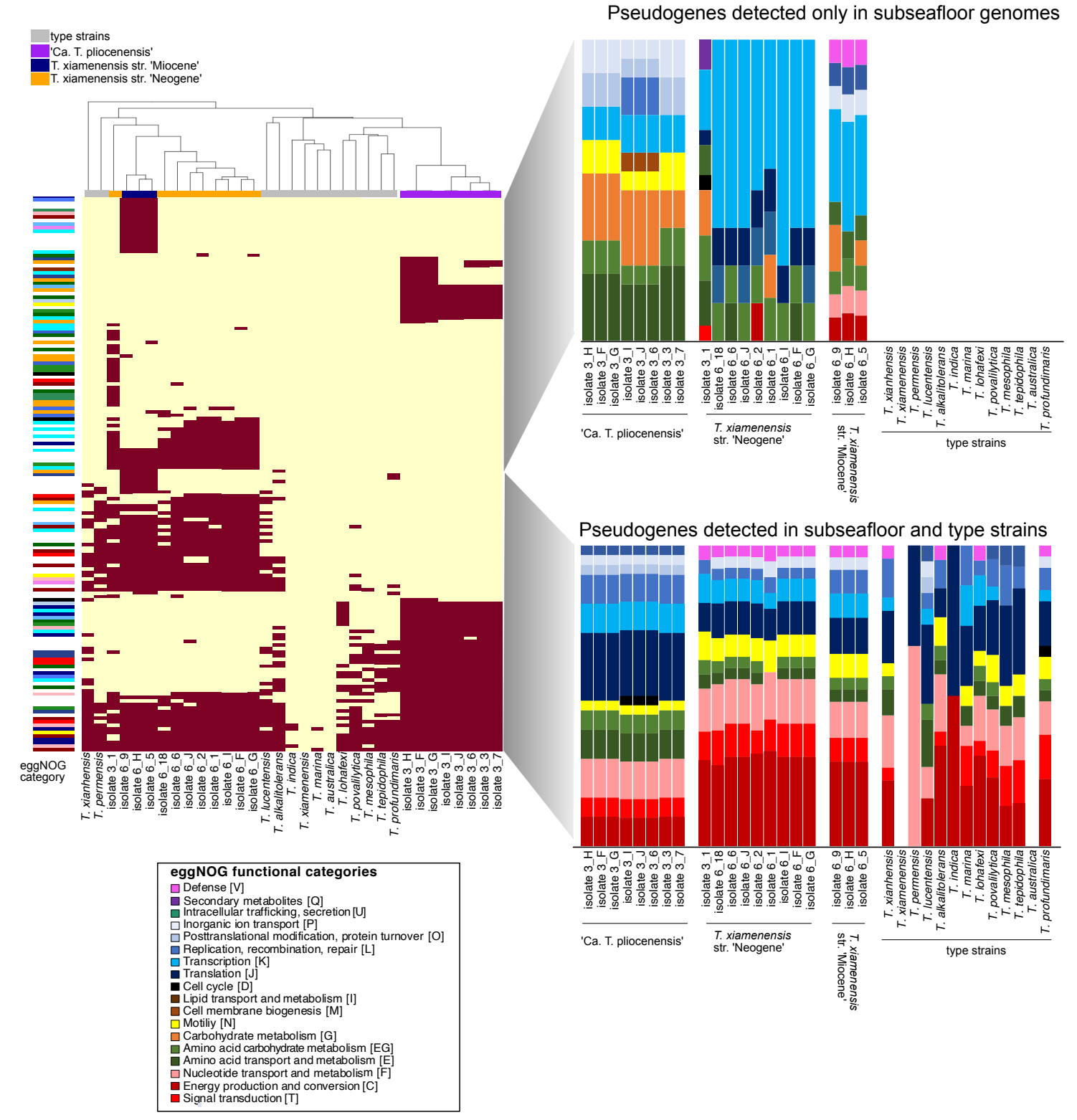


594 Figure S10: Histograms showing the average relative abundance of functional categories in

595 pseudogenes found within each of the three subseafloor populations, compared to the type

596 strains. The error bars represent standard deviations, and asterisks indicate functional categories

597 of pseudogenes that were significantly higher in the subseafloor genomes compared to the type

598 strain genomes (two sided T-Test, $\mathrm{P}<0.01$ ).

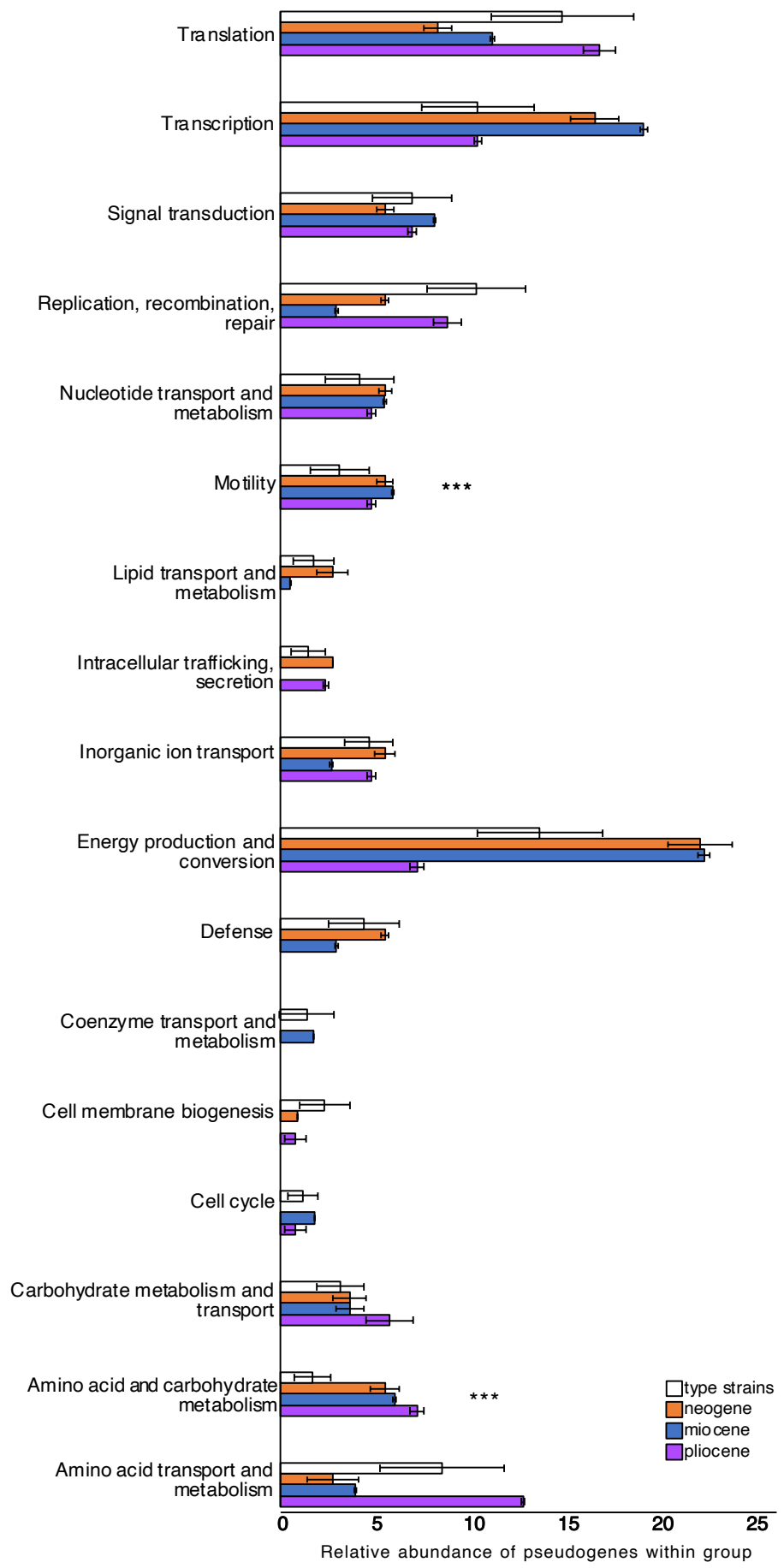




\section{Materials and Methods}

601 Sampling and pore water chemistry. All samples were taken during Expedition KN223 of the $R / V$ 602 Knorr in the North Atlantic, from 26 October to 3 December 2014 . At site $11\left(22^{\circ} 47.0^{\prime} \mathrm{N}, 56^{\circ} 31.0^{\prime} \mathrm{W}\right.$, 603 water depth $\sim 5600 \mathrm{~m})$ via a long core piston-coring device $(\sim 28 \mathrm{~m})$. Additional details of sampling are 604 published elsewhere $(11,13)$. Dissolved oxygen concentrations in the core sections were measured with 605 optical $\mathrm{O}_{2}$ sensors from the equilibrated core sections and measured with needle-shaped optical $\mathrm{O}_{2}$ 606 sensors (optodes) (PreSens, Regensburg, Germany) as described previously $(11,13)$. The dissolved $\mathrm{O}_{2}$ 607 data from Expedition KN223 are archived and available online in the Integrated Earth Data Applications 608 (IEDA) database (http://www.iedadata.org/doi?id=100519).

\section{Physical sediment properties.}

Deep-sea abyssal clay is characterized by very low permeability and extremely small pore diameter,

611 despite its high porosity (15). Deep sea clay particles have a grain size of $<0.2 \mu \mathrm{m}$, and the pore space

612 between clay particles is smaller than a bacterial cell, limiting the movement of bacteria through pore space

613 in the clay. Bioturbation can vertically redistribute cells within marine sediment, but bioturbation is 614 restricted to the upper 0.5 meters of sediment (31), and thus cannot vertically transport sediment surface 615 material and microbes to depths of 3 and 6 mbsf. Considering the mean sedimentation rate of $1 \mathrm{~m}$ per 616 million years, it can be concluded that the bacterial cultures obtained from sediment collected at 3 and 6 617 mbsf have been physically isolated from the surface world for millions of years.

619 DNA extraction, qPCR, 16S rRNA gene sequencing. DNA extractions, qPCR, and 16S rRNA gene 620 sequencing were performed previously and described in Vuillemin et al (12). In brief, subcores were 621 sampled aseptically with sterile syringes were subsampled aseptically in an ultraviolet (UV)-sterilized

622 DNA/RNA clean HEPA- filtered laminar flow hood. DNA extraction was extracted from $10 \mathrm{~g}$ of

623 sediment transferred into $50 \mathrm{ml}$ of Lysing Matrix E tubes (MP Biomedicals) containing silica glass beads

624 and homogenized for $40 \mathrm{~s}$ at $6 \mathrm{~m} / \mathrm{s}$ using a FastPrep-24 5G homogenizer (MP Biomedicals) in the 625 presence of $15 \mathrm{ml}$ of preheated $\left(65^{\circ} \mathrm{C}\right)$ sterile- filtered extraction buffer [76 volume \% $1 \mathrm{M} \mathrm{NaPO} 4(\mathrm{pH}$

626 8), 15 vol- ume \% 200 proof ethanol, 8 volume \% MoBio's lysis buffer solution C1, and 1 volume \%

627 SDS]. The samples were incubated at $99^{\circ} \mathrm{C}$ for 2 min and frozen overnight at $-20^{\circ} \mathrm{C}$, thawed, and frozen

628 again at $-20^{\circ} \mathrm{C}$ overnight, followed by additional incubation at $99^{\circ} \mathrm{C}$ for $2 \mathrm{~min}$ and a second

629 homogenization using the settings described above. After the second homogenization, the samples were 630 centrifuged for $15 \mathrm{~min}$, and the supernatants were concentrated to a volume of $100 \mathrm{ml}$ using $50-\mathrm{kDa}$ 631 Amicon centrifugal filters (Millipore). Coextracted PCR-inhibiting humic acids and other compounds 
were removed from the concentrated extract using the PowerClean Pro DNA Cleanup Kit (MoBio).

633 Extraction blanks were performed alongside the samples to assess laboratory contamination during the

634 extraction process.

DNA was quantified fluorometrically using a Qubit with a double- stranded DNA high-sensitivity kit (Life Technologies). qPCR was performed using the custom primer dual indexed approach that tar-

637 gets the V4 hypervariable region of the 16S rRNA gene using updated 16S rRNA gene primers

638 515F/806R (515F, 5'-GTGYCAG- CMGCCGCGGTAA-3'; 806R, GGACTACNVGGGTWTCTAAT)

639 (32). Barcoded V4 hypervariable regions of amplified 16S rRNA genes were sequenced on an Illumina

640 MiniSeq following an established protocol (33). Bioinformatic processing of these previously published

641 sequence data is described by Vuillemin et al (12) in detail.

643 Long term incubation set up. Prior to setting up the incubations, the subcores were sampled with sterile

644 syringes using the sample aseptic technique used for the DNA extraction. For each sample depth, seven

645 grams of abyssal clay was placed into sterile $20-\mathrm{mL}$ glass flasks and incubated with $4 \mathrm{~mL}$ of sterile

646 artificial seawater composed of either $\mathrm{H}_{2}{ }^{18} \mathrm{O}(97 \%$ atomic enrichment) or unlabeled artificial seawater.

647 Vials were crimp sealed, with an oxygenated headspace of approximately $10 \mathrm{~mL}$, and incubated at $8{ }^{\circ} \mathrm{C}$.

648 The artificial seawater was different from the porewater at depth because there was no added nitrate, but

649 there was also no added ammonia which should be similar to the in situ conditions where ammonia is

650 generally below detection (12). Oxygen was measured continuously throughout the incubations using

651 non-invasive fiberoptic measurements as described previously (12). Small fluctuations in the oxygen

652 measurements in the killed control, and experimental incubations, were likely due to temperature

653 fluctuations of the incubator itself $\left( \pm 1^{\circ} \mathrm{C}\right)$, since the non-invasive fiber optic oxygen sensor spots are

654 temperature sensitive (12). Oxygen consumption was detectable over 18 months in slurries consisting of

655 sediment and sterile artificial seawater (Fig S1), suggesting the presence of actively respiring microbes.

656 We used qSIP to measure the atom $\%{ }^{18} \mathrm{O}$-enrichment of actively growing microbial taxa

657 as described previously (12). In brief, after 7 and 18 months incubations DNA was extracted and

658 subjected to Cesium Chloride $(\mathrm{CsCl})$ density gradient centrifugation. The same $16 \mathrm{~S} 515 \mathrm{~F} / 806 \mathrm{R}$

659 primers (described above) were used in qPCR (described above) to determine density shifts in

660 the peak DNA of buoyant density (BD) for each incubation. 16S rRNA gene amplicons from

661 each fraction resulting from the density gradient fractionation were Illumina sequenced as

662 described previously (12). To identify contaminants that may have entered during the 
663 fractionation process, we also included in the sequencing run extraction blanks from the SIP

664 fractionation. OTUs containing sequences from extraction blanks were removed. Excess atm\%

$665{ }^{18} \mathrm{O}$-enrichment was calculated for each OTU (including OTU6, corresponding to the subseafloor

666 Thalassospira) according to the equations for quantifying per OTU atomic enrichment.

667 The number of doublings for the Thalassospira OTU (OTU_6) detected at the 18 month

668 timepoint was calculated using qPCR normalized relative abundance of the 16S rRNA genes at

669 T0 and 18 months. The number of doublings was divided by the total number of days incubated

670 to calculate doubling times in days.

671

672 Enrichments, cultivation, and sub-cultivation. After the 18 months of incubation in sterile ${ }^{18} \mathrm{O}-$ labeled

673 artificial seawater, $25 \mu \mathrm{L}$ of slurry was plated onto solid media $(10 \mathrm{mg} / \mathrm{mL}$ yeast extract and $8 \mathrm{mg} / \mathrm{mL}$

674 agar in artificial seawater $\left[30 \mathrm{mM} \mathrm{MgCl}_{2} \cdot 6 \mathrm{H}_{2} \mathrm{O}, 16 \mathrm{mM} \mathrm{MgSO}_{4} \cdot 7 \mathrm{H}_{2} \mathrm{O}, 2 \mathrm{mM} \mathrm{NaCO}_{3}, 10 \mathrm{mM} \mathrm{KCl}, 9\right.$

$675 \mathrm{mM} \mathrm{CaCl}_{2}, 450 \mathrm{mM} \mathrm{NaCl}$ )] ), and after 2 days incubated in the dark at room temperature, abundant

676 colonies were observed growing on the surface of the petri dishes (Fig S1). No colonies were observed to

677 grow on control petri dishes that received $25 \mu \mathrm{L}$ of ${ }^{18} \mathrm{O}$-labeled artificial seawater slurry incubated for 18

678 months using starting material from autoclaved sediment (killed controls). This indicated that the colony-

679 forming bacteria were from the sediment and not contaminants introduced during the experimental set up

680 of the incubations. We attempted to culture chemoheterotrophic microbes directly from the collected

681 sediment samples using the same conditions, but no colony-forming units were observed on the petri

682 dishes, even after several months of incubation. Thus, long-term incubation of the sediment at $8{ }^{\circ} \mathrm{C}$

683 simply in the presence of added water apparently stimulated the activity of many subseafloor bacteria to a

684 point at which they were able to grow on the surface of a petri dish.

685 Twelve colonies were picked from petri dishes containing colonies from the 3-mbsf and 6-mbsf

686 slurries. These colonies were streaked individually onto twelve separated new petri dishes, and a single

687 colony was picked from each of the twelve petri dishes (representing an original colony forming unit from

688 the enrichment) and grown in sterile liquid media $(10 \mathrm{mg} / \mathrm{mL}$ yeast extract and $8 \mathrm{mg} / \mathrm{mL}$ agar in artificial

689 seawater $\left[30 \mathrm{mM} \mathrm{MgCl}_{2} \cdot 6 \mathrm{H}_{2} \mathrm{O}, 16 \mathrm{mM} \mathrm{MgSO}_{4} \cdot 7 \mathrm{H}_{2} \mathrm{O}, 2 \mathrm{mM} \mathrm{NaCO}_{3}, 10 \mathrm{mM} \mathrm{KCl}, 9 \mathrm{mM} \mathrm{CaCl}_{2}, 450\right.$

$690 \mathrm{mM} \mathrm{NaCl}$ )]). Single colonies were then grown up in liquid media. A portion of each of these colonies

691 was used for DNA extraction and genome sequencing, and the remaining volume was frozen as glycerol

692 stocks. Growth rates were determined in experiments with $20 \mathrm{~mL}$ crimp sealed glass flasks containing

$6930.1 \mathrm{~mL}$ of glycerol stock inoculated into $10 \mathrm{~mL}$ liquid media $(10 \mathrm{mg} / \mathrm{mL}$ yeast extract in artificial

694 seawater $\left[30 \mathrm{mM} \mathrm{MgCl}_{2} \cdot 6 \mathrm{H}_{2} \mathrm{O}, 16 \mathrm{mM} \mathrm{MgSO}_{4} \cdot 7 \mathrm{H}_{2} \mathrm{O}, 2 \mathrm{mM} \mathrm{NaCO}_{3}, 10 \mathrm{mM} \mathrm{KCl}, 9 \mathrm{mM} \mathrm{CaCl}_{2}, 450\right.$

$695 \mathrm{mM} \mathrm{NaCl}$ )]) with $10 \mathrm{~mL}$ headspace, and gentle shaking. The optical density at $600 \mathrm{~nm}$ was measured 
once every 30 minutes with a spectrophotometer, and growth rates were calculated from the exponential phase. Under these conditions, growth rates of the subseafloor Thalassospira were similar across all three clades and ranged from 0.064 to $0.31 \mathrm{~h}^{-1}$ (Fig. S5).

\section{Assessing the possibility for genome evolution during the 18 month enrichment.}

Because bacteria can evolve on lab experimental timescales $(5,6)$ we considered the possibility that all diversification and evolution happened during the 1.5 year enrichment. Using the qPCR-based estimate for doubling time of the subseafloor Thalassospira OTU (OTU_6) in the incubation which was $36( \pm 1.5)$ days, the number of doublings with this rate over this time period would be approximately 15 . According to "Drake's rule (20), bacteria experience on average one mutation per 300 genomes replicated; thus, the amount of nucleotide diversity (hundreds to thousands of mutations: Fig S8) that could be accumulated during the incubation is insufficient to explain the observed divergence between the three subseafloor populations. We thus conclude that the inter-population nucleotide diversity resulted from mutations that were acquired after they were buried.

Genome sequencing, de novo assembly, and annotation. DNA was extracted from the isolates grown in

712 liquid culture until the end of exponential phase as described above. After reaching stationary phase,

713 cultures were pelleted via centrifugation and the supernatant was decanted. The cell pellets were 714 resuspended in a preheated $\left(65^{\circ} \mathrm{C}\right)$ sterile filtered extraction buffer [76 volume \% $1 \mathrm{M} \mathrm{NaPO} 4(\mathrm{pH} 8), 15$ 715 volume $\% 200$ proof ethanol, 8 volume \%MoBio lysis buffer solution C1, and 1 volume \% SDS], and added 716 to lysing matrix E tubes (MP Biomedicals) containing silica glass beads and homogenized for $40 \mathrm{~s}$ at $6 \mathrm{~m} / \mathrm{s}$ 717 using a FastPrep-24 5G homogenizer (MPBiomedicals). The samples were centrifuged for $15 \mathrm{~min}$, and the 718 dissolved high molecular weight DNA in the supernatant was concentrated to a volume of $100 \mu \mathrm{L}$ using $71950-\mathrm{kDa}$ Amicon centrifugal filters (Millipore). The concentrated extract was cleaned of proteins and other 720 non-genomic DNA organic matter using the PowerClean Pro DNA Cleanup Kit (MoBio). Extraction blanks 721 were performed alongside the samples to assess laboratory contamination during the extraction process. 722 Genomic libraries were prepared using the Nextera XT DNA Library Prep Kit (Illumina). Quality control 723 and quantification of the libraries were obtained on an Agilent 2100 Bioanalyzer System using the High 724 Sensitivity DNA reagents and DNA chips (Agilent Genomics). Metagenomic libraries were diluted to 1 725 nM using the Select-a-Size DNA Clean and Concentrator MagBead Kit (Zymo Research) and pooled for 726 further sequencing on the Illumina MiniSeq platform. Genomic libraries were sequenced to a depth of ca. 727 100x coverage using a high-output paired end 2 x 150 sequencing regent kit (Illumina).

728 In addition to Illumina sequencing, the high molecular weight genomic DNA was sequenced using the 729 NanoPore MinION. Sequencing libraries for the MinION were prepared using the Ligation Sequencing kit 
730 (Oxford NanoPore Technologies), according to the manufacturers instructions. Barcoded libraries were 731 sequenced on the MinION using a Flongle R9 flow cell, base-called and demultiplexed using the MinIT 732 with ont-minit-release v19.12.5 and ont-guppy-for-minit v3.2.10 for base calling (Oxford NanoPore 733 Technologies).

734 A hybrid assembly was performed using both the short (Illumina) and long (NanoPore) read 735 sequencing data using Unicycler (v.0.4.0), which uses de novo assembled Illumina data from SPADES to 736 polish the de novo assembled contigs obtained from NanoPore data using RACON (34). The combined 737 assemblies of Illumina and NanoPore data resulted in a relative low number of contigs (9-12 per genome), 738 and a predicted genome completeness of $100 \%$ of nearly all genomes (Table S1). Genome completeness was determined using CheckM (35). Genomes were annotated using RASTk (36).

Core genome phylogenetic analyses. The core genome was defined as the set of orthologous genes which were shared in all subseafloor and extant Thalassospira genomes. Orthologous genes were defined as those sharing $>30 \%$ amino acid similarity to the collective suite of genes encoded within the type strain Thalassospira xiamenensis M-5. T. xiamenensis M-5 was chosen as the reference genome for this purpose, because it is the only publicly available genome of a cultivated Thalassospira isolate that is completely closed and represents a single chromosome and a $190 \mathrm{~Kb}$ plasmid (14). A total of 1,809 orthologous genes were identified that are encoded by all Thalassospira strains that had $>30 \%$ sequence similarity to genes encoded within the T. xiamenensis M-5 genome. Each of these 1,809 genes was individually aligned between all Thalassospira strains using MUSCLE (37), and the individual 1,809 alignments were then concatenated into a single core genome alignment for the subsequent phylogenomic analysis (ClonalFrameML, HyPhy, aBRSEL) using Geneious Prime (version 2019.2.1). After concatenation of all core genes, the total size of the core genome alignment was 1,817,073 nucleotide characters, and 34 taxa (21 subseafloor strains, and 13 type strain taxa). A Maximum-Likelihood phylogeny was created using PhyML (38) with a GTR model of evolution and 100 bootstrap replicates, which was implemented within SeaView (39). The resulting phylogenetic tree and the concatenated core genome alignment were used as inputs for subsequent ClonalFrameML and $\mathrm{dN} / \mathrm{dS}$ analyses.

The contributions of mutations and recombination to the genomic diversity in the concatenated core genome alignment, the number of recombination events (imports) per genome, and the positions of recombination hot spots, were investigated using ClonalFrameML (19). Nucleotides unaffected by recombination are referred to as unimported and nucleotides subject to recombination are referred to as imported (19). ClonalFrameML provides the relative rate of recombination to mutation (R/Theta), the mean length of recombined DNA (Delta), and the mean divergence of imported DNA ( $\mathrm{Nu}$ ). These results were used to calculate the relative contribution of recombination versus mutation to the overall genomic diversity 
$764(\mathrm{r} / \mathrm{m})$, using the formula $\mathrm{r} / \mathrm{m}=(\mathrm{R} /$ Theta $) *$ Delta $* \mathrm{Nu}$. ClonalFrameML was performed in three separate 765 runs, respectively containing a core genome alignment that contained (1) all genomes, (2) only the 766 subseafloor genomes, and (3) only the type strains. The resulting $\mathrm{r} / \mathrm{m}$ values from these three groups

767 (presented in Table 1) were then used to interpret the relative importance of mutations compared to 768 recombination, in the separate groups (e.g., type strains versus subseafloor strains).

769 In addition to calculating sites and rates of recombination in the core genome, ClonalFrameML 770 also estimates the ancestral sequences at internal nodes of the clonal genealogy, and any missing base calls 771 in the observed sequences. The reconstruction of ancestral sequence states is performed using maximum 772 likelihood and the ClonalFrame model can be thought of as a hidden Markov model (HMM) when the 773 ancestral and descendant genomes for each branch of the clonal genealogy have been observed or 774 reconstructed (19). The hidden state of the HMM records whether each nucleotide was subject to 775 recombination or not on the branch connecting the two genomes. We acknowledge that drawing inference 776 under the resulting ancestral recombination graph is a notoriously complex statistical problem (19). Instead, 777 here we use ClonalFrameML only to assess within-group recombination (e.g., between species within the 778 genus Thalassospira), and thus our analysis cannot assess the influence of external recombination (from 779 species outside the genus Thalassospira).

780 The ratio of non-synonymous $(\mathrm{dN})$ to synonymous $(\mathrm{dS})$ mutations in the core genome alignment 781 (global $\omega$ ratio) was estimated using HyPhy v2.2.4 (40), and applying the adaptive branch-site random782 effects likelihood (aBSREL) approach (41) to all branches in all subfamilies. Because of the high similarity 783 of the subseafloor genomes, aBSREL was run multiple times using the core genome alignment with only 784 one representative of the nearly identical subseafloor genomes included in each separate run. For each of 785 these runs, one representative genome of T. xiamenensis strain 'Neogene', T xiamenensis strain 'Miocene, 786 and 'Ca. T. pliocenensis' were included together with all other Thalassospira type strain genomes in each aBSREL run. Then, the aBSREL run was repeated with the same type strains but different subseafloor genomes from those same three clades, until dN/dS estimates were obtained for all subseafloor genomes.

Pangenome analysis. All subseafloor and extant Thalassospira genomes were analyzed in Anvi'o v6.2 using pangenome workflow (42). Briefly, each genome was converted into an anvi'o contigs database.

792 Genes were functionally annotated using eggnog v5.0 (43) with eggNOG-mapper (44) and imported back 793 to each genome's anvi'o contig database. Genome storages were generated using 'anvi-gen-genomes794 storages' and 'anvi-pan-genome' was deployed with parameters '--min-bit 0.5' (45), '--mcl-inflation' 10 795 (46), and the flag '--use-ncbi-blast' (47). The anvi'o pan database and summary of gene clusters stored in 796 FIGshare (https://figshare.com/s/06ba1287a00ab01a1ee). 
799 Identifying pseudogenes. We estimated the number of pseudogenes within the genomes using two 800 programs, Psi-Phi (48) and DFAST (49). Psi-Phi uses a conservative criterion considering a pseudogene 801 only when it lost $>20 \%$ of its original length, and enhances pseudogene recognition among closely related 802 strains both in annotated regions by identifying incorrectly annotated open reading frames (ORFs) and in 803 intergenic regions by detecting new pseudogenes (48). Psi-Phi classifies pseudogenes as either identified 804 pseudogenes and those as being possible, but potentially not pseudogenes. To be conservative, we only considered genes identified as pseudogenes from Psi-Phi and did not consider those flagged as 'potential pseudogenes'. As a second check of pseudogene content, we searched genomes for pseudogenes using DFAST (49). The estimated number of pseudogenes per genome was then taken as an average of the numbers detected both using both methods (Psi-Phi and DFAST). On average, Psi-Phi identified a higher number of pseudogenes per genome $(57 \pm 10)$ compared to DFAST $(32 \pm 4)$, but the variation between methods for the same genome was consistent (average variation $=27$, standard deviation of averages $=7$ ).

811 This minimal variation between individual genomes indicates that biases inherent to the pseudogene 812 prediction methods affected the different genomes equally, and thus allow for a pseudogene comparison 813 between the genomes.

31. L. R. Teal, M. T. Bulling, E. R. Parker, M. Solan, Global patterns of bioturbation intensity and mixed depth of marine soft sediments. Aquatic Biology 2, 207-218 (2008)

32. A. E. Parada, D. M. Needham, J. A. Fuhrman, Every base matters: assessing small subunit rRNA primers for marine microbiomes with mock communities, time series and global field samples. Environ Microbiol 18, 1403-1414 (2016).

33. M. Pichler et al., A 16S rRNA gene sequencing and analysis protocol for the Illumina MiniSeq platform. Microbiologyopen, e00611 (2018).

34. R. R. Wick, L. M. Judd, C. L. Gorrie, K. E. Holt, Unicycler: Resolving bacterial genome assemblies from short and long sequencing reads. PLoS Comput Biol 13, e1005595 (2017).

35. D. H. Parks, M. Imelfort, C. T. Skennerton, P. Hugenholtz, G. W. Tyson, CheckM:

36. R. Overbeek et al., The SEED and the Rapid Annotation of microbial genomes using assessing the quality of microbial genomes recovered from isolates, single cells, and metagenomes. Genome Res 25, 1043-1055 (2015).

\section{Subsystems Technology (RAST). Nucleic Acids Res 42, D206-214 (2014).}

37. R. C. Edgar, MUSCLE: multiple sequence alignment with high accuracy and high throughput. Nulceic Acids Res 32, 1792-1797 (2004). 
38. S. Guindon, F. Lethiec, P. Duroux, O. Gascuel, PHYML Online--a web server for fast maximum likelihood-based phylogenetic inference. Nucleic Acids Res 33, W557-559 (2005).

39. M. Gouy, S. Guindon, O. Gascuel, SeaView version 4: A multiplatform graphical user interface for sequence alignment and phylogenetic tree building. Mol Biol Evol 27, 221224.

40. S. L. Pond, S. D. Frost, S. V. Muse, HyPhy: hypothesis testing using phylogenies. Bioinformatics 21, 676-679 (2005).

41. M. D. Smith et al., Less is more: an adaptive branch-site random effects model for efficient detection of episodic diversifying selection. Mol Biol Evol 32, 1342-1353 (2015)

42. A. M. Eren et al., Anvi'o: an advanced analysis and visualization platform for 'omics data. PeerJ 3, e1319 (2015).

43. J. Huerta-Cepas et al., eggNOG 5.0: a hierarchical, functionally and phylogenetically annotated orthology resource based on 5090 organisms and 2502 viruses. Nucleic Acids Res 47, D209-D314 (2018).

44. J. Huerta-Cepas et al., Fast Genome-Wide Functional Annotation through Orthology Assignment by eggNOG-Mapper. Mol Biol Evol 34, 2115-2122 (2017).

45. M. N. Benedict et al., ITEP: and integrated toolkit for exploration of microbial pangenomes. BMC Genomics 15, 12.1186/1471-2164-15-8 (2014).

46. S. van Dongen, C. Abreu-Goodger, Using MCL to extract clusters from networks. In "Bacterial Molecular Networks: Methods and Protocols" Eds. J. van Helden, A. Toussaint, D. Thieffry. Springer New York, New York, NY. Pages 281-295.

47. S. F. Altschul et al., Basic local alignment search tool. J Mol Biol 215, 403-410 (1990).

48. E. Lerat, H. Ochman, Psi-Phi: exploring the outer limits of bacterial pseudogenes. Genome Res 14, 2273-2278 (2004). pipeline for faster genome publication. Bioinformatics 34, 1037-1039 (2018). 